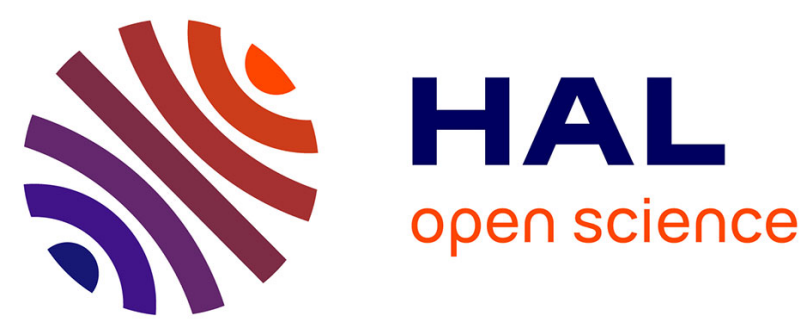

\title{
Blue Chemistry. Marine Polysaccharide Biopolymers in Asymmetric Catalysis: Challenges and Opportunities
}

Daniel Antonio Aguilera, Nathalie Tanchoux, Mariafrancesca Fochi, Luca Bernardi

\section{- To cite this version:}

Daniel Antonio Aguilera, Nathalie Tanchoux, Mariafrancesca Fochi, Luca Bernardi. Blue Chemistry. Marine Polysaccharide Biopolymers in Asymmetric Catalysis: Challenges and Opportunities. European Journal of Organic Chemistry, 2020, 2020 (25), pp.3779-3795. 10.1002/ejoc.201901924 . hal-02912960

\section{HAL Id: hal-02912960 \\ https://hal.umontpellier.fr/hal-02912960}

Submitted on 22 Dec 2020

HAL is a multi-disciplinary open access archive for the deposit and dissemination of scientific research documents, whether they are published or not. The documents may come from teaching and research institutions in France or abroad, or from public or private research centers.
L'archive ouverte pluridisciplinaire HAL, est destinée au dépôt et à la diffusion de documents scientifiques de niveau recherche, publiés ou non, émanant des établissements d'enseignement et de recherche français ou étrangers, des laboratoires publics ou privés. 


\title{
Blue Chemistry. Marine Polysaccharide Biopolymers in Asymmetric Catalysis: Challenges and Opportunities
}

\author{
Daniel Antonio Aguilera, ${ }^{[a, b]}$ Nathalie Tanchoux, ${ }^{*[a]}$ Mariafrancesca Fochi, ${ }^{[b]}$ and Luca Bernardi ${ }^{*[b]}$
}

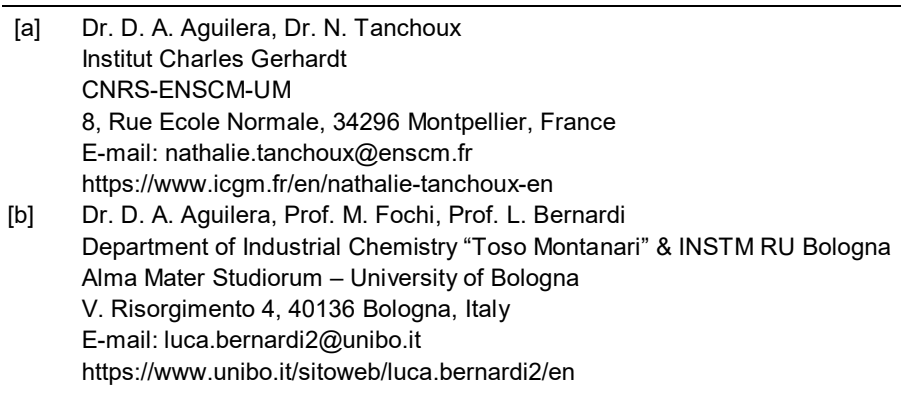

\begin{abstract}
Alginate, chitin (precursor of chitosan) and carrageenan are natural polysaccharides derived from marine sources and available in nearly unlimited amounts. In contrast with other natural polysaccharides (i.e. cellulose), their monomers bear functional groups (amine, carboxylate, sulfate). These functional groups can be used to anchor catalytic species, or even as catalytically active units. In this mini-review, the utilization of marine polysaccharides in asymmetric catalysis is discussed. Examples include: $\mathrm{i}$ ) combinations with chiral catalysts, resulting in heterogeneous catalytic systems, and ii) utilization of the biopolymers as chirality inducing elements - serving as chiral ligands or organocatalysts. The reviewed works propose innovative and unconventional utilizations of these renewable materials, providing not only a useful alternative to oil-based polymers, but also unforeseen and fascinating opportunities in the field of asymmetric catalysis.
\end{abstract}

\section{Introduction}

Increasing environmental concerns call for an urgent switch from depleting resources to renewable ones. In this alarming context, it is essential to increase the exploitation of biomass, derived from waste, or obtained without competing with agriculture and food production. The broad concept of bio-refinery, ${ }^{[1]}$ wherein biomass processing replaces oil-based technologies, includes creative and often unforeseeable conversion of biomass into novel materials. Such strategic valorisation of biomass, complementing its more common downgrade conversion to fuels and bulk/commodity chemicals, is gaining fast pace. Mass-intensive uses go along with high-tech applications of new biomass-derived materials with tailored properties. ${ }^{[2]}$

In this mini-review, we highlight the emerging utilization in asymmetric catalysis (excluding biocatalysis) of three families of polysaccharides extracted from marine sources: chitin/chitosan $(\mathbf{C t} / \mathbf{C h})$, alginates $(\mathbf{A g})$, and $\mathrm{K}$-carrageenan $(\mathbf{C r})$ (Figure 1).

These three families of biopolymers are available in nearly unlimited amounts at very low prices, with plant scale extraction processes providing $>45^{\prime} 000$ tonn $/ Y$ worldwide. ${ }^{[3]}$ Chitosan, the partially deacetylated form of chitin, is obtained from seafood shell waste, or from fungi; alginates are instead extracted from brown macro-algae, while carrageenans from red algae. They are used as stabilisers, emulsifiers, thickening agents, etc. in different industrial settings (e.g. paper, dyes, food, pharmaceutical, cosmetic industries), and as supports for enzymes and whole cells in brewing processes and laundry powder formulations.

Structurally speaking, these three families are constituted by different monosaccharide units in defined conformations, and all bear a functional group in their structure (chitosan - primary amine; alginates - carboxylic acid; carrageenan - sulfuric acid). Amongst the carrageenans, we keep the focus on k-carrageenan, which carries only one sulfate group, since it presents the best properties for gelation. ${ }^{[4]}$ The presence of a functional group in these biopolymers is in contrast with other natural polysaccharides, such as cellulose, starch, agar, dextran, etc., which show only hydroxyl groups at their surfaces. Given that each monomer of chitosan and alginates, or each two monomers in the case of $\mathrm{k}$-carrageenan, carries one functionality, the functional group density in these materials is high. For example, alginic acid features a $5.8 \mathrm{mmol} / \mathrm{g}$ density of carboxylic acid functionalities, while each gram of chitosan brings up to $6.2 \mathrm{mmol}$ of primary amines.

Daniel Antonio Aguilera obtained his $\mathrm{PhD}$ in Chemistry in 2019 under the frame of the European Doctoral Programme on Sustainable Industrial Chemistry (SINCHEM) at the National School of Chemistry of Montpellier (ENSCM, France) and the University of Bologna (Italy) under the supervision of Dr Nathalie Tanchoux and Prof Luca Bernardi. His research focused on the use of alginate-based materials as supports and catalysts for asymmetric reactions of interest in fine chemistry. From 2011 to 2016, he was professor in the University of the Llanos, Colombia teaching General Chemistry, Biochemistry and Physical Chemistry, he was also Director of the Department of Biology and Chemistry and Director of the Water Quality Centre. He received his BSc (2008) and MSc degree (2010) in Chemistry from the National University of Colombia. His academic interests range from heterogeneous catalysts to organocatalysis. 
Nathalie Tanchoux obtained her PhD degree from the University Claude Bernard Lyon, in 1999 under the supervision of Dr. Claude de Bellefon and Dr. Daniel Schweich. From October 2000, she joined the French CNRS (National Center of Scientific Research) in the Institute Charles Gerhardt in Montpellier, France. Since 2016, she is the scientific leader of the research group "From Renewable Resources to Materials and Molecules" (R2M2) within the MACS

(Matériaux Avancés pour la Catalyse et la Santé) team. She has expertise in heterogeneous catalysis, materials synthesis and characterization. Her current research interests are focused on aerogels synthesis from marine polysaccharides for catalytic applications. The work already achieved has shown the interest of the alginate route to synthesize supported and unsupported metallic oxides for catalytic applications, as well as hierarchical materials from algal resource for catalysis and adsorption. She is part of the editorial board of the open-access journal "Gels" and has acted as guest editor for two special issues on "Aerogels" in 2016 and 2018. Since 2016, she is a member of the Catalysis Division of the French Society of Chemistry and has been elected in 2019 president of the French Catalysis Division.

\section{Mariafrancesca Fochi was born in Parma}

(Italy), received her Master Degree in Industrial Chemistry in 1994 and the Ph.D. in 1998 from the University of Bologna with Prof. A. Ricci. She spent research periods as academic visitor at the University of Nijmegen (The Netherlands) under the supervision of Prof. B. Zwanenburg and at the Oxford University (UK) with Prof. J. M. Brown. In 2004, she was appointed assistant professor, and in 2019 associate professor, at the University of Bologna. Her scientific interests include acylsilanes and thioacylsilanes chemistry, chiral ferrocene derivatives, metal-mediated homogeneous asymmetric catalysis and finally asymmetric organocatalysis. She is co-author of more than 80 papers published in international journals
Luca Bernardi studied Industrial Chemistry at the University of Bologna (Italy) (MSc, 2000). He then carried out his PhD studies in synthetic organic chemistry (Prof. A. Ricci) in Bologna which were completed in 2004. After postdoctoral stays in Aarhus, Denmark (2004 and 2006, with Prof. K. A. Jørgensen), in 2007 he was back at the University of Bologna, where he was appointed assistant professor in 2011, and associate professor in 2014. In 2011-2012, he spent four months as a visiting scientist at the University of Groningen (NL, with Prof. B. L. F. Feringa). His research work, mainly directed at the development of new organocatalytic enantioselective reactions, was recognized by the Thieme Journal Prize in 2009, and by the Ciamician medal of the Organic Chemistry Division of the Italian Chemical Society in 2010.

In line with their natural function, these polysaccharides readily form stable hydrogels under appropriate conditions. Conversion to solvogel and aerogel is also possible, providing wet or dry materials of high surface areas $\left(>200 \mathrm{~m}^{2} / \mathrm{g}\right)$, which structure mirrors the one of the parent hydrogel. A perhaps less appreciated feature of these biopolymers is the possibility to finetune their mechanical, physical and chemical properties in different manners. For example, the ratio between the mannuronic and guluronic units of alginate has a dramatic effect on the mechanical properties of the resulting gels. Alginates with higher guluronic content give stiffer and more resistant materials. This ratio depends on the natural source of the biopolymer (type, growth conditions of the algae, part of the plant from which alginate is extracted), and can thus be chosen with care depending on the target application. Another example of possible fine-tuning is the adjustment of the basicity of chitosan as desired through its deacetylation degree. The $\mathrm{N}$-acetyl groups exert a subtle influence on the electronics of the free amine functions, allowing a fine control over the basicity of the material through the deacetylation degree. ${ }^{[8]}$

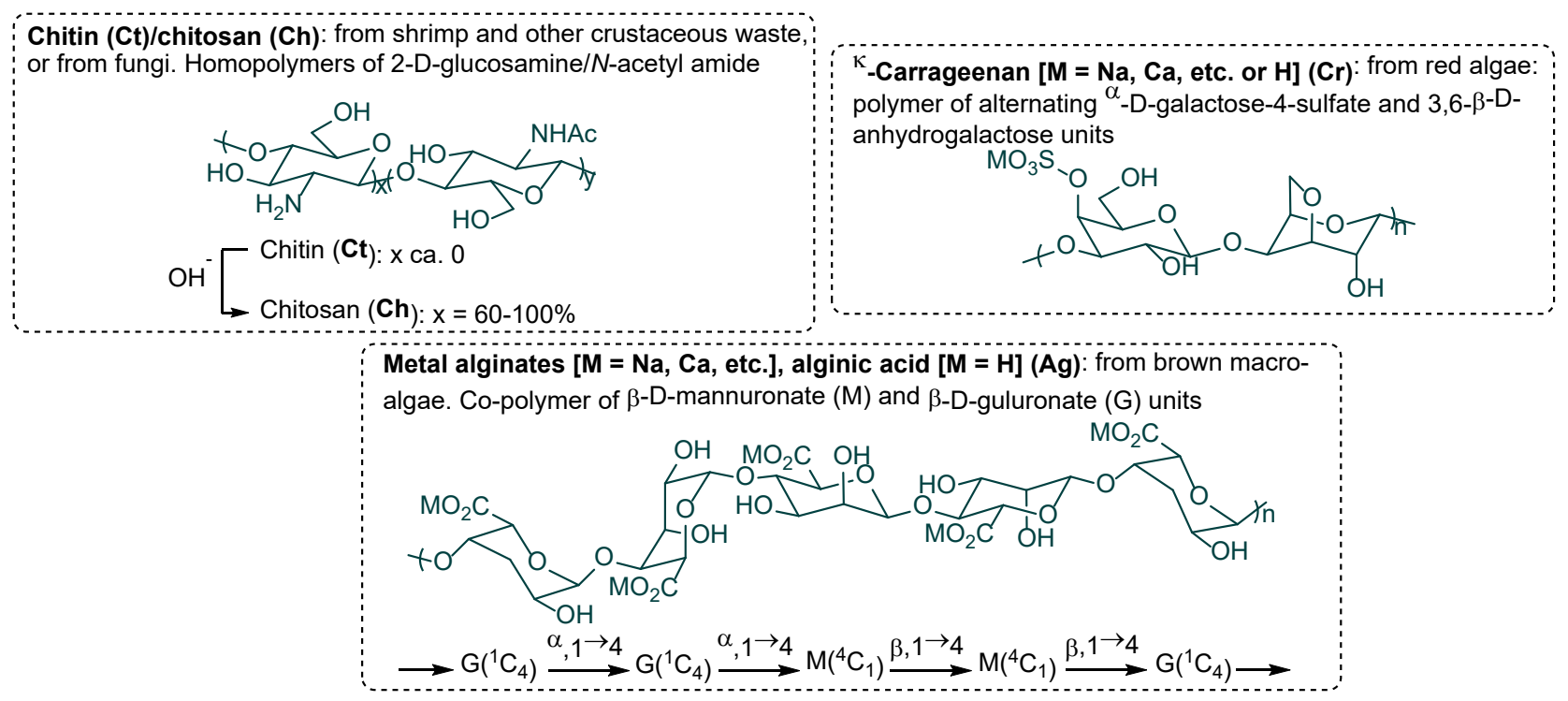


Overall, these biopolymers can form highly functionalized, porous materials of high surface areas, insoluble, yet stable, in different media including water. Considering also that they are very easily manageable in the form of gel beads, these materials have all credentials to become important players as supports for heterogeneous catalytic processes. Indeed, applications of these biopolymers in supporting metal species and nanoparticles, for a range of non-enantioselective reactions, have been widely explored. ${ }^{[9]}$ Considerable attention has also been paid to the possibility of using directly these bio-based materials as heterogeneous catalysts, i.e. by exploiting the substrate activation offered by their embedded functionalities. ${ }^{[9]}$

In the context of asymmetric catalysis, polysaccharides cannot be considered as conventional supports for chiral catalysts This stands in sharp contrast with enzymatic and whole-cell systems, that make widespread use of polysaccharides as stabilizing support matrixes. ${ }^{[10]}$ Typical supports for (chiral) low molecular weight catalytic species are polystyrene and other resins, silica, inorganic salts, etc. ${ }^{[11]}$ Nonetheless, several examples demonstrating the possible exploitation of these renewable polysaccharides for immobilizing chiral catalytic species, and more specifically organic catalysts, ${ }^{[12]}$ are emerging, as summarized and discussed in section 2 .

An added bonus of these natural materials is their intrinsic homochirality. However, the transfer of this chiral information through a catalytic enantioselective process affording enantioenriched products appears to be challenging. For example efforts to develop an enantioselective process with chitosan, carrageenan and alginate-palladium assemblies, in an allylic amination reaction, were unsuccessful. ${ }^{[13]}$ It was considered that these materials lack a homogenous, well-defined, chiral tertiary structure, i.e. the typical helixes - useful as chirality inducing elements - of other biopolymers such as oligonucleotides and oligopeptides. ${ }^{[14]}$ Hypothesizing that such tertiary structures would be required for enantioinduction, only the highly ordered crystalline parts of the biopolymers would provide enantioselectivity. However, these are not easily reachable by the reactants. A more recent report describing the requirement of a crystalline form of another polysaccharide, i.e. nanocellulose, to effect an enantioselective reaction (asymmetric hydrogenation with palladium nanoparticles), seems to corroborate this hypothesis. ${ }^{[15]}$ More recently, in the study of metal alginate catalysed Henry reactions, the embedment of the catalytically active metal centre in the swollen biopolymer matrix was thought to cause a shielding effect, preventing the assembly of a highly ordered transition state, thus leading to racemic products. ${ }^{[16]}$ Despite these discouraging reports, there are indeed examples available, limited to chitosan, wherein the biopolymer has been able to induce enantioselectivity in various reactions. These examples are reported in section 3 .

\section{Marine polysaccharide supported chiral catalysts}

\subsection{Chitosan}

The first example of the utilization of chitosan in asymmetric catalysis, without attempting to exploit its homochirality, has been reported by Cui and co-workers in 2009. ${ }^{[17]}$ Asserted aim of this work was the disclosure of a chiral catalyst able to work efficiently in water. They took into consideration L-proline, a prototypical small molecule catalyst, and one of its most relevant catalytic transformations, the aldol reaction. Proline is not able to catalyse efficiently the aldol reaction in water. In contrast, enzymes are in general superb catalysts in aqueous media. Enzymatic reactions occur in the hydrophobic active site of the enzyme. Cui and coworkers speculated that a chitosan-proline combination in water could function as an enzyme mimic. They hypothesized that the chitosan macromolecule could provide the required hydrophobic pocket, wherein the proline-catalysed reaction could occur. On the other hand, some of these authors had already shown the utility of chitosan microspheres in supporting palladium complexes for Mizoroki-Heck reactions in water. ${ }^{[18]}$ Accordingly, they set up to functionalize the amine groups of chitosan with Lproline units (Scheme 1). Functionalization was performed by treating an aqueous solution of chitosan $(\mathrm{pH}=2-3$ to guarantee dissolution) with Fmoc-protected proline acyl chloride, followed by Fmoc deprotection with aqueous ammonia, $\mathrm{EtOH}$ induced precipitation, and collection of the resulting solid $\mathrm{Ch} 1$ by filtration.
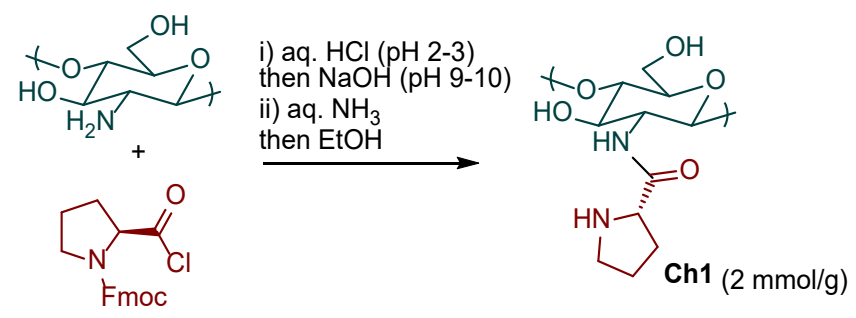

Scheme 1. Preparation of L-proline-grafted chitosan Ch1

Such powdered chitosan Ch1, grafted with L-proline units (2 $\mathrm{mmol} / \mathrm{g}$ ), was then tested in the aldol reaction between cyclohexanone and para-nitrobenzaldehyde (Table 1). Remarkably, better results in terms of reactivity and selectivity were obtained by using polar protic solvents, that is $\mathrm{EtOH}$ and in particular water, as reaction media (entries 3,4 ). The reaction in other polar solvents (DMF, DMSO, entries 1,2 ) typically employed in proline catalysed reactions, required longer times or provided lower stereoselectivities. These results were rationalized considering that water could break the intramolecular hydrogen bond network of chitosan, allowing swelling and unfolding of the chains of this macromolecule. Thus, substrates can reach the catalytically active units of Ch1 (i.e. the proline functions), and catalysis occurs. Furthermore, water can act as a co-catalyst in this type of enamine mediated reactions. Speculating that the introduction of an additional hydrophobic portion in the system would improve its efficiency, the authors screened different typical surfactants in the reaction. Such screening identified the non-ionic tween-20 as the most promising surfactant (entry 5). Compared to the reaction in pure water, it led in fact to an improvement in terms of productivity ( $85 \%$ vs $50 \%$ yield), diastereo- (anti/syn $90: 10$ vs $75: 25)$ and enantio-selectivity (92\% vs $72 \%$ ). The catalyst could be used for at least three times with similar results (entries 6,7), highlighting a good stability of this heterogeneous system. 
Table 1. Aldol addition of cyclohexanone to para-nitrobenzaldehyde catalysed by $\mathrm{Ch} 1$ under various reaction conditions: selected results.

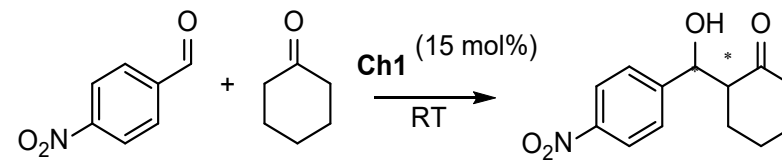

\begin{tabular}{|c|c|c|c|c|c|c|}
\hline Entry & Solvent & Additive & $t[d]$ & $\mathrm{Y}[\%]$ & Antilsyn & $e e^{[a]}[\%]$ \\
\hline 1 & DMF & - & 10 & 61 & $77: 23$ & 38 \\
\hline 2 & DMSO & - & 10 & 53 & 71:29 & 57 \\
\hline 3 & $\mathrm{EtOH}$ & - & 10 & 44 & $59: 41$ & 74 \\
\hline 4 & $\mathrm{H}_{2} \mathrm{O}$ & - & 3 & 50 & $75: 25$ & 72 \\
\hline 5 & $\mathrm{H}_{2} \mathrm{O}$ & Tween-20 & 3 & 85 & 90:10 & 92 \\
\hline $6^{[b]}$ & $\mathrm{H}_{2} \mathrm{O}$ & Tween-20 & 3 & 78 & 89:11 & 87 \\
\hline $7^{[c]}$ & $\mathrm{H}_{2} \mathrm{O}$ & Tween-20 & 3 & 80 & $89: 11$ & 90 \\
\hline
\end{tabular}

[a] ee of anti diastereoisomer. [b] Second run. [b] Third run.

The scope of this aldol reaction in water was studied using cyclohexanone and acetone as aldol donors, and various electron-poor aromatic aldehydes as acceptors (Scheme 2). A transition state model, revisited in Scheme 2, was proposed to account for the stereoinduction for the reactions with cyclohexanone as donor. The opposite selectivity, in terms of aldehyde pro-chiral face when using acetone as donor, was not rationalized. On other hand, subsequent studies highlighted the importance of thermodynamic control in the proline-catalysed reaction with cyclohexanone as donor. ${ }^{[19]}$ The proposed model takes into account the involvement of an enamine derived from the condensation between the donor and proline as nucleophilic component. At the same time, activation of the aldehyde electrophile was proposed to occur via the 4-hydroxy group of the sugar. Unfortunately, control experiment, by using for example Dproline in the grafting, were not reported. Such experiments could assess the influence of the homochirality of the biopolymer on reaction outcome, and the plausibility of the proposed transition state model.

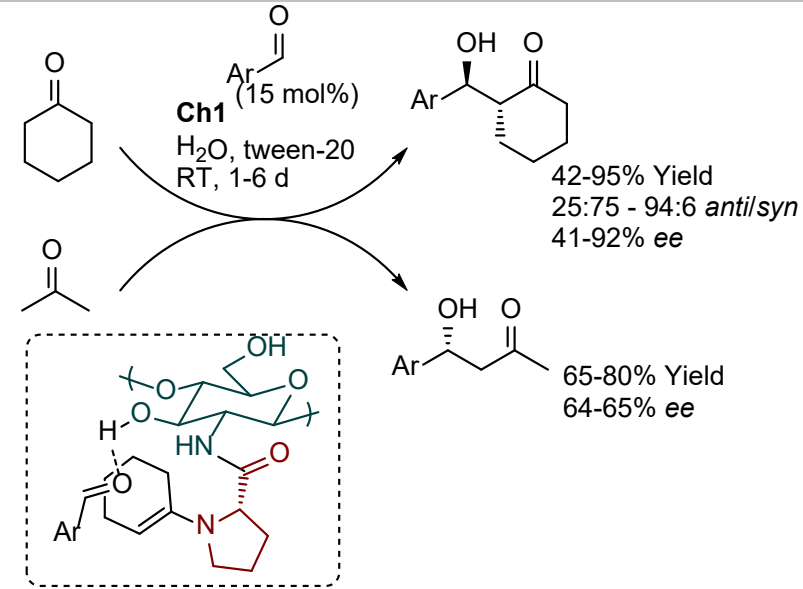

Scheme 2. Scope of the aldol reaction catalysed by $\mathrm{Ch} 1$, and proposed transition state model for cyclohexanone reactions.

An attempt to use this catalyst Ch1 in a mechanistically distinct reaction (the Henry addition) gave only disappointing results in terms of enantioselectivity $\left(<10 \%\right.$ ee) ${ }^{[20]}$ On the other hand, even the parent chitosan biopolymer could catalyse the racemic reaction. Conversely, few years later, the same laboratory reported the functionalization of the same biopolymer with Cinchona alkaloids, resulting in the chitosan supported 9deoxy-9-amino quinine $\mathrm{Ch} 2$ and the corresponding cinchonine derivative Ch3. ${ }^{[21]}$ The aim of this work was to find a replacement to commonly used polystyrene resins in the heterogenization of these catalysts. Catalysts $\mathbf{C h} 2$ and $\mathbf{C h} 3$, which stereochemistry at C9 appears uncertain, were applied to the enantioselective addition of 3-ketoesters and 1,3-diketones to $\mathrm{N}$-benzyl maleimide, delivering the products with good results, even by using a nonswelling solvent such as toluene (Scheme 3). As expected, the quinine derivative $\mathrm{Ch} 2$ and its cinchonine counterpart $\mathrm{Ch} 3$ gave the two enantiomers of the Michael adducts. Catalyst Ch2 could be recovered and reused five times with minimal loss of efficiency. Subsequent studies by the same authors disclosed another approach to Cinchona anchored to chitosan, including a spacer and their application to aldol reactions with good results. ${ }^{[22]}$

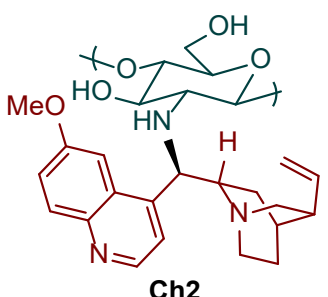

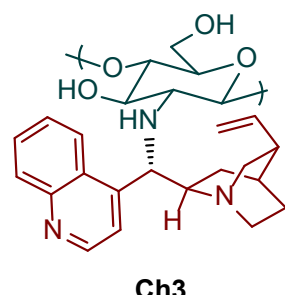

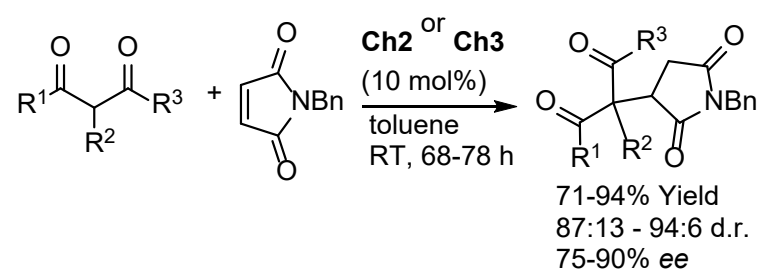

Scheme 3. Cinchona-grafted chitosan catalysts $\mathrm{Ch} 2$ and $\mathrm{Ch} 3$, and their application to the addition of dicarbonyl compounds to $\mathrm{N}$-benzyl maleimide. 
The interest in finding a sustainable replacement of commonly employed resins for immobilization, thus preparing a supported catalyst featuring renewability and biodegradability, stands back the work reported recently by Andrés, Pedrosa and co-workers. ${ }^{[23]}$ In more detail, a series of thiourea catalysts Ch4-11 were prepared by functionalizing the amine group of chitosan (high molecular weight, $94.5 \%$ degree of deacetylation) by various means (reductive amination, thiourea formation, etc.). Functionalization was performed under acidic conditions $(\mathrm{AcOH} / \mathrm{MeOH}$ mixtures) to ensure chitosan solubilisation. The resulting catalysts, obtained in powdered form and featuring different degrees of effective functionalization ( $f$, in $\mathrm{mmol} / \mathrm{g}$, based on sulfur content determined by elemental analysis) were evaluated in the aza-Henry addition of nitromethane to benzaldehyde-derived $\mathrm{N}$-Boc imine (Scheme 4). Reactions were performed under neat conditions. The catalysts bearing the thiourea function directly linked to the biopolymer chain $(\mathbf{C h 4 , 5 )}$ were not active in the reaction. This was attributed to the difficult approach to the catalytic units by the reactants. In contrast, all other catalysts Ch6-11 gave the expected aza-Henry product with moderate to good results. Structures Ch10 and Ch11, with a longer spacer and at the same time a more acidic 3,5bis(trifluoromethyl)phenyl thiourea function, proved to be more efficient in terms of enantioselectivity. The loading of catalyst Ch11 could be lowered to $5 \mathrm{~mol} \%$ without compromising reactivity nor selectivity. Furthermore, it could be recovered by simple filtration, and reused at least five times with only a small decrease in yield. Such catalyst appears to be very stable.
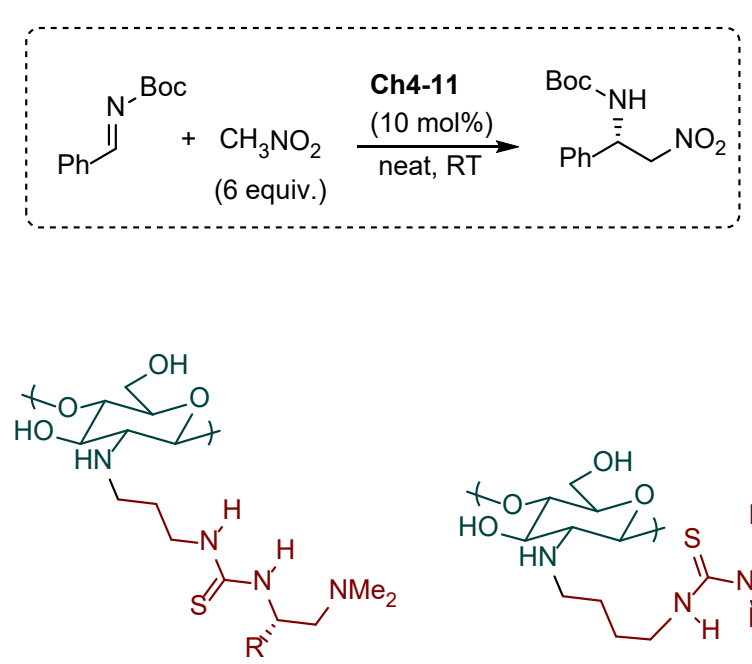

Ch6: $\mathrm{R}=i-\operatorname{Pr}(f=1.33)$

$22 \mathrm{~h}: 65 \%$ Yield, $72 \%$ ee

Ch7: $\mathrm{R}=\mathrm{Bn}(f=1.39)$

$20 \mathrm{~h}: 62 \%$ Yield, $76 \%$ ee
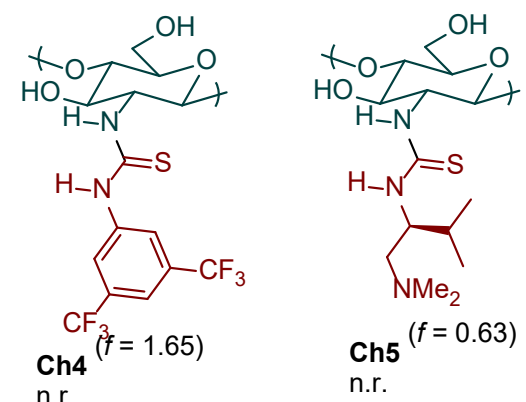

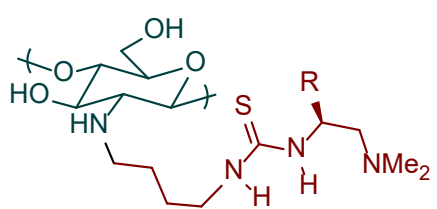

Ch8: $\mathrm{R}=i-\operatorname{Pr}(f=0.67)$

$22 \mathrm{~h}: 72 \%$ Yield, $64 \%$ ee

Ch9: $\mathrm{R}=\mathrm{Bn}(f=0.48)$

$30 \mathrm{~h}: 65 \%$ Yield, $64 \%$ ee

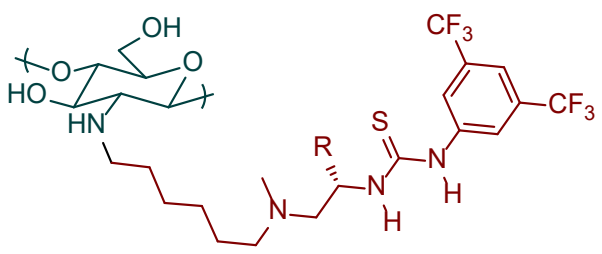

Ch10: $\mathrm{R}=i-\operatorname{Pr}(f=1.73)$

$30 \mathrm{~h}: 70 \%$ Yield, $84 \%$ ee

Ch11: $\mathrm{R}=\mathrm{Bn}(f=1.55)$

$10 \mathrm{~h}: 72 \%$ Yield, $86 \%$ ee

$5 \mathrm{~mol} \%, 14 \mathrm{~h}: 70 \%$ Yield, $86 \%$ ee

reusable $>5$ reaction cycles

Scheme 4. Evaluation of a small library of bifunctional tertiary amine-thiourea catalysts anchored to chitosan (Ch4-11) in an enantioselective aza-Henry reaction.

The scope of the reaction was inspected by reacting various $\mathrm{N}$-Boc imines with nitromethane and higher nitroalkanes, providing in all cases the corresponding products with moderate to good results (Scheme 5). The possible effect of the homochirality of the chitosan in these reactions, by using for example the enantiomeric amino-thiourea appendage, was not evaluated.<smiles></smiles>

$\mathrm{X}=\mathrm{H}, \mathrm{CF}_{3}, \mathrm{Cl}$, $\mathrm{Me}, \mathrm{NO}_{2}, \mathrm{MeO}$

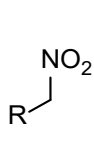

Ch11 (5 mol\%) 6-36 h

$\mathrm{R}=\mathrm{H}, \mathrm{Me}, \mathrm{Et}$ (6 equiv.)

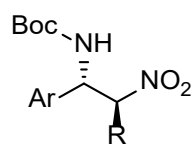

$66-82 \%$ Yield $78: 22-84: 16$ d.r. $62-90 \%$ ee
To conclude this subsection, it might be instructive to compare some of these chitosan supported catalysts with representative polystyrene derived counterparts. ${ }^{[2]}$ As shown in Scheme 6, a polystyrene derived prolinamide $\mathbf{P s} \mathbf{1}^{[24 \mathrm{a}]}$ appears more active and stereoselective than chitosan derived $\mathbf{C h} 1$ in the benchmark aldol reaction, although the presence of a spacer between catalyst and support in Ps1 might contribute to its better performances. Reusability does not seem very different, at least according to the data reported. Ch1 could be used for at least three consecutive runs. Ps1, at $5 \mathrm{~mol} \%$ loading, required a reactivation procedure after three runs, to restore catalyst activity and provide good results in the fourth run. Such reactivation (treatment with formic acid) has been very successful for a more complex and structurally unrelated polystyrene supported prolinamide catalyst. ${ }^{[24 b]}$ 
<smiles>O=C[C+]1CCCCC1C(=O)c1ccc([N+](=O)[O-])cc1</smiles>

\begin{tabular}{l|l|l|l} 
Catalyst & Conditions & Results & Reusability \\
\hline Ch1 & $\mathrm{H}_{2} \mathrm{O} /$ Tween-20 & $\begin{array}{l}85 \% \text { Yield } \\
\text { (15 mol\%) }\end{array}$ & 5 equiv. ketone \\
& $\mathrm{RT}, 3 \mathrm{~d}$ & $\begin{array}{l}90 \mathrm{~d} \text { d.r. } \\
92 \% \text { ee }\end{array}$ & \\
\hline Ps1 & $\mathrm{H}_{2} \mathrm{O}, \mathrm{AcOH}$ & $91 \%$ Yield & $>4$ runs \\
(5 mol\%) & 2 equiv. ketone & $92: 8 \mathrm{~d} . r$. & (with regeneration) \\
& $0{ }^{\circ} \mathrm{C}, 24 \mathrm{~h}$ & $92 \%$ ee &
\end{tabular}<smiles>COC(O)C(CO)NC(=O)[C@@H]1CCCN1</smiles>

Ch1 $(2 \mathrm{mmol} / \mathrm{g})$

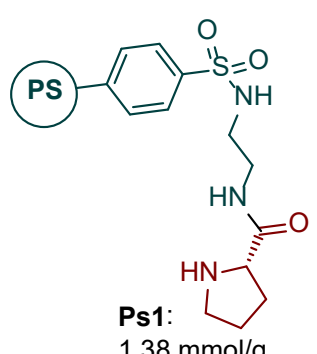

$1.38 \mathrm{mmol} / \mathrm{g}$

Scheme 6. Comparison of the performances of $\mathbf{C h} 1$ and its polystyrene derived counterpart Ps 1 in the aldol reaction between cyclohexanone and paranitrobenzaldehyde.

A comparison between the chitosan derived bifunctional catalyst Ch11, and its corresponding polystyrene supported counterpart Ps2, ${ }^{[24 c]}$ is displayed in Scheme 7 for the prototypical aza-Henry addition of nitromethane to $N$-Boc benzaldimine. The polystyrene supported catalyst Ps2 appears more active and stereoselective than the chitosan derived one (Ch11), even if there is not a dramatic difference between the two catalysts. Furthermore, robustness and reusability of these catalysts seems to be very similar. Besides, chitosan is cheaper and more readily available than the polystyrene sulfonyl chloride resin used to prepare Ps2 (<1 €/gram vs ca. $15 € / g r a m$, Sigma-Aldrich catalogue). Thus, it can be concluded that, at least for these catalysts, chitosan does constitute an appealing alternative support to polystyrene resins for catalyst heterogenization.

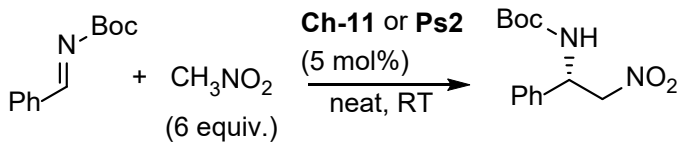

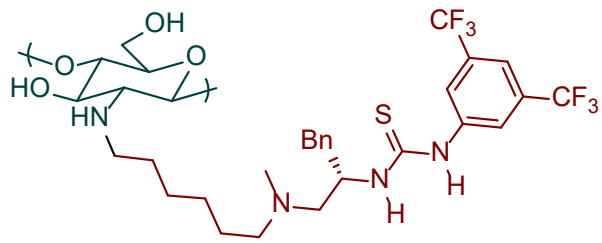

Ch11: 14 h, $70 \%$ Yield, $86 \%$ ee reusable $>5$ reaction cycles

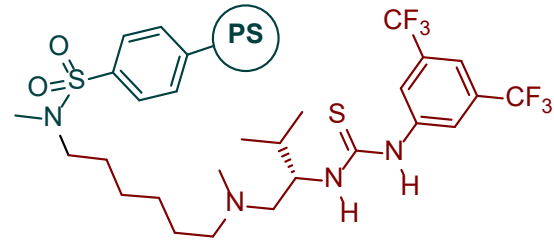

Ps2: 6 h, $82 \%$ Yield, 96\% ee reusable $>5$ reaction cycles

\section{2. $\mathrm{k}$-Carrageenan}

The presence of the sulfate group in natural $\mathrm{k}$-carrageenan was exploited by Pericàs and co-workers for coating iron magnetic nanoparticles (MNPs). The resulting hybrid organicinorganic material was subsequently functionalized to enable the immobilization of a diphenylprolinol silyl ether catalyst. ${ }^{[25]}$ In more detail, spherical, monodisperse $(4.8 \pm 0.9 \mathrm{~nm}$ by TEM) magnetic nanoparticles were prepared by thermal decomposition of $\mathrm{Fe}(\mathrm{acac})_{3}$ in the presence of oleylamine and oleic acid as surfactants. ${ }^{[26]}$ These MNPs were then treated with $\mathrm{k}$-carrageenan, in the presence of $\mathrm{AcOH}$, water, $\mathrm{DMF}$, and heated to $110{ }^{\circ} \mathrm{C}$ (Scheme 8). Such obtained hybrid material $\mathrm{Cr} 1$, with similar shape and size as the parent MNPs, was itself active as catalyst in the addition of aldehydes to nitroalkenes. The single components - MNPs and K-carrageenan, with and without $\mathrm{AcOH}$ treatment - were instead not active. Nevertheless, the adducts were invariably obtained in racemic form, and the mechanism of substrate activation by the synergistic combination of MNPs and $\mathrm{K}$-carrageenan was not understood. Thus, functionalization with a chiral organic catalyst, to use the hybrid magnetic nanomaterial Cr1 as a support, was undertaken. Appel reaction, azide substitution followed by copper catalysed azide-alkyne cycloaddition (CUAAC) with a 4-propargyloxy diphenyl prolinol derivative, ultimately afforded the immobilized aminocatalyst $\mathrm{Cr} 2$ It was used in the same addition of aldehydes to nitroalkenes previously explored with $\mathrm{Cr} 1$, delivering this time the products with very good enantioselectivities. It can be remarked that the catalyst Cr2 could be separated from the reaction mixture by magnetic decantation, thanks to the presence of the MNPs in the hybrid support. However, its activity in subsequent cycles was not reported.

Scheme 7. Comparison between $\mathrm{Ch} 11$ and the corresponding polystyrene derived catalyst Ps2 in the benchmark aza-Henry reaction. 


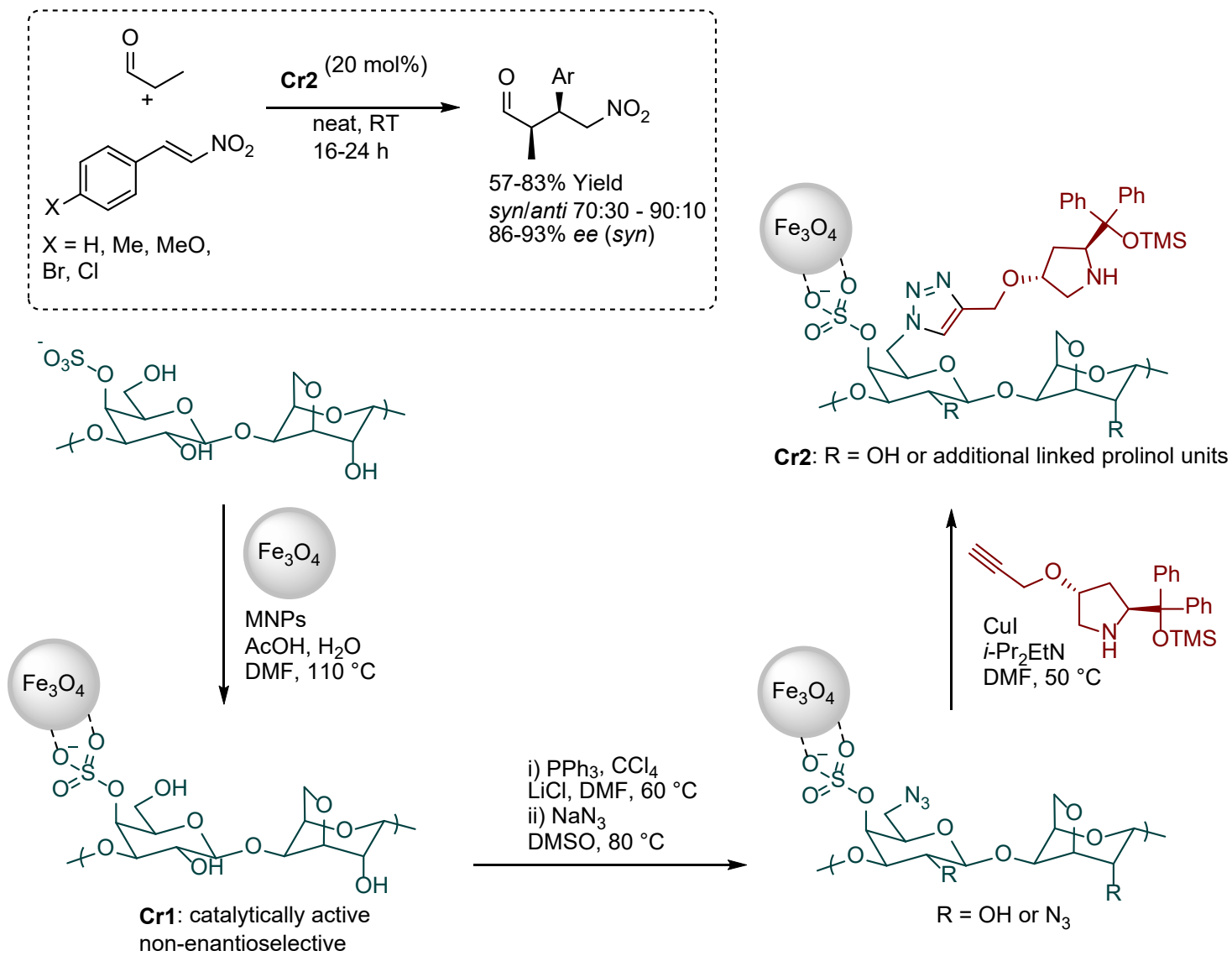

Scheme 8. k-Carrageenan MNPs hybrid material $\mathrm{Cr} 1$ and its use to anchor a prolinol catalyst (Cr2).

\subsection{Alginate}

The first application of alginates in asymmetric catalysis has been recently disclosed by our laboratories. ${ }^{[27]}$ Besides the use of a distinct polysaccharide, this work departs from the ones summarized in the previous subsections for two additional reasons. i) Alginate gels (aerogel and solvogel beads) were employed throughout the project, for both catalyst immobilization and enantioselective reaction. In the previous examples, biopolymers were dissolved in a suitable medium to react with a functional group installed in the catalyst, ensuring immobilization, and then converted to powders. These powders of low surface areas had to swell in the medium used for the catalytic reaction. We envisioned that using gel beads could lead to a heterogeneous material, carrying the catalytic species, characterized by high surface area, outstanding manageability, and employability to different reaction media (i.e. it is already swelled). ii) Catalyst immobilization was based on adsorption, that is, on non-covalent interactions between the catalyst (9-amino-9deoxy epi-quinine) and the support (alginic acid), instead of covalent anchoring of the catalyst to the biopolymer. Such approach to catalyst immobilization, while being more prone to catalyst leaching compared to the more common covalent anchoring, does not require synthetic manipulations to link the catalyst to the support. Furthermore, it leads to heterogenized chiral catalysts keeping more degrees of freedom that when anchored via covalent bonds, thus potentially leading to selectivities equivalent to those obtained by homogeneous catalysts. This strategy, intrinsically straightforward, has been especially useful in heterogeneous aminocatalysis, wherein the acidic functions of the support can act both as anchoring units by interaction with a basic function of the catalyst, and as cocatalysts by assisting different steps of the complex catalytic cycle of aminocatalytic reactions. ${ }^{[28]}$

Different challenges had to be faced at the outset of the project. The most significant one was to devise a robust adsorption protocol delivering stable alginic acid gel beads encapsulating the primary amine catalyst. In fact, the carboxylic protons, responsible for catalyst adsorption through an acid-base interaction with the amine catalyst, are also essential for the stability of the gel structure. Indeed, rupture of the gel beads was observed in several preliminary experiments. Ultimately, it was found that using a relatively stiff alginate biopolymer, rich in guluronic acid monomers, EtOH/ $\mathrm{H}_{2} \mathrm{O}$ 9:1 as adsorption medium under high dilution, and a ca. $2.5: 1$ ratio between the carboxylic functions of the alginate and the amine, a stable and robust solvogel beads material Ag1 incorporating most of the amine catalyst added to the mixture could be produced (Scheme 9). The use of an "excess" of carboxylic acid functions during adsorption preserved the stable gel structure. UV/Vis/DRS and FT-IR spectroscopy confirmed adsorption and that the main interaction between the catalyst and support is acid-base in nature. 


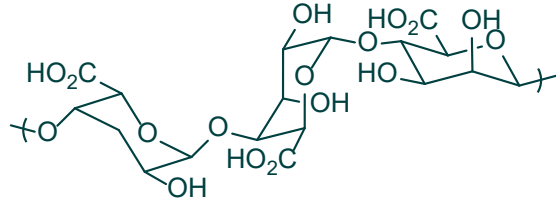

Alginic acid (guluronic rich) gel beads

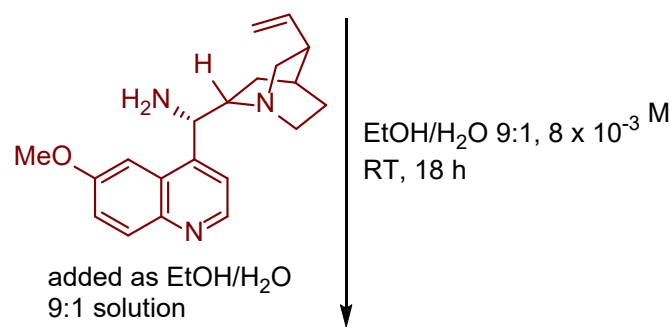

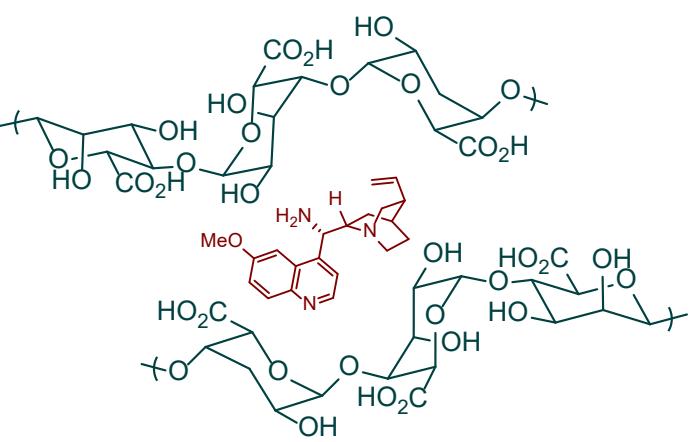

Ag1: alginic acid beads encapsulating amine catalyst: adsorption yield $84 \%$

Scheme 9. Adsorption of 9-amino-9-deoxy epi-quinine on alginic acid gel.

Such beads Ag1 were applied with good results to the enantioselective Michael addition of iso-butyraldehyde to a paratrifluoromethylphenyl nitroalkene, which was used in order to follow the reaction progress by ${ }^{19} \mathrm{~F}$ NMR. Sheldon tests demonstrated good heterogeneity of the catalysis, suggesting minimal catalyst leaching during the catalytic process (Scheme 10).

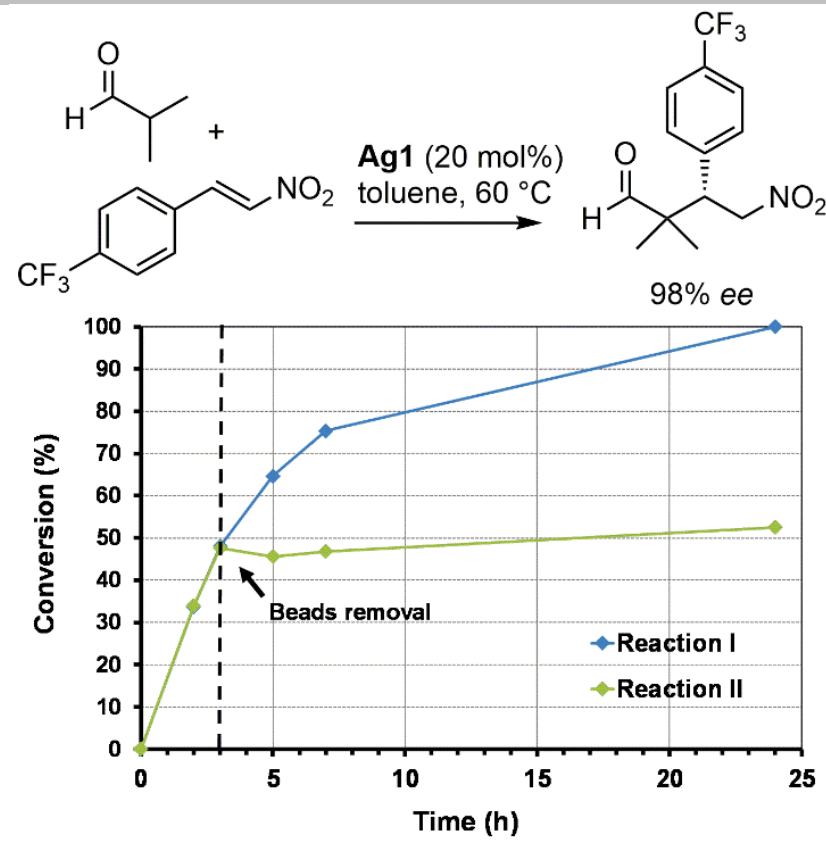

Scheme 10. Application of Ag1 to the addition of iso-butyraldehyde to a paratrifluoromethyl nitrostyrene. Reaction kinetics and Sheldon test. Conversion determined by ${ }^{19} \mathrm{~F}$ NMR spectroscopy.

Additional investigations were carried out with heterocationic alginate gels, obtained by proton exchange from alkaline metal earth $(\mathrm{Ca}, \mathrm{Sr}, \mathrm{Ba})$ alginates (Scheme 11). These latter gels are characterized by a more dispersed structure and better mechanical properties. For example, while the surface area of an alginic acid aerogel was measured to be ca. $250 \mathrm{~m}^{2} / \mathrm{g}$, calcium alginate aerogel have surface areas of about $350-500 \mathrm{~m}^{2} / \mathrm{g}^{[13]} \mathrm{It}$ was hypothesized that the higher dispersity of alkaline earth metal alginate gels could be at least partially preserved during the proton exchange process. Under the conditions reported in Scheme 9, the proton exchange left ca. $10-20 \mathrm{~mol} \%$ of the initial metal salt in the material, as determined by TGA analysis. Ultimately, heterocationic alginate gels were found to be highly competent in adsorbing the amine. Moreover, the resulting Ag2 Ag4 showed an improved catalytic activity compared to the parent Ag1, as can be seen from the kinetic curves reported in Scheme 9. It was concluded that the above mentioned higher dispersities of Ag2-Ag4, compared to Ag1, gave the substrates easier access to the catalytic units, ultimately resulting in higher activity. 


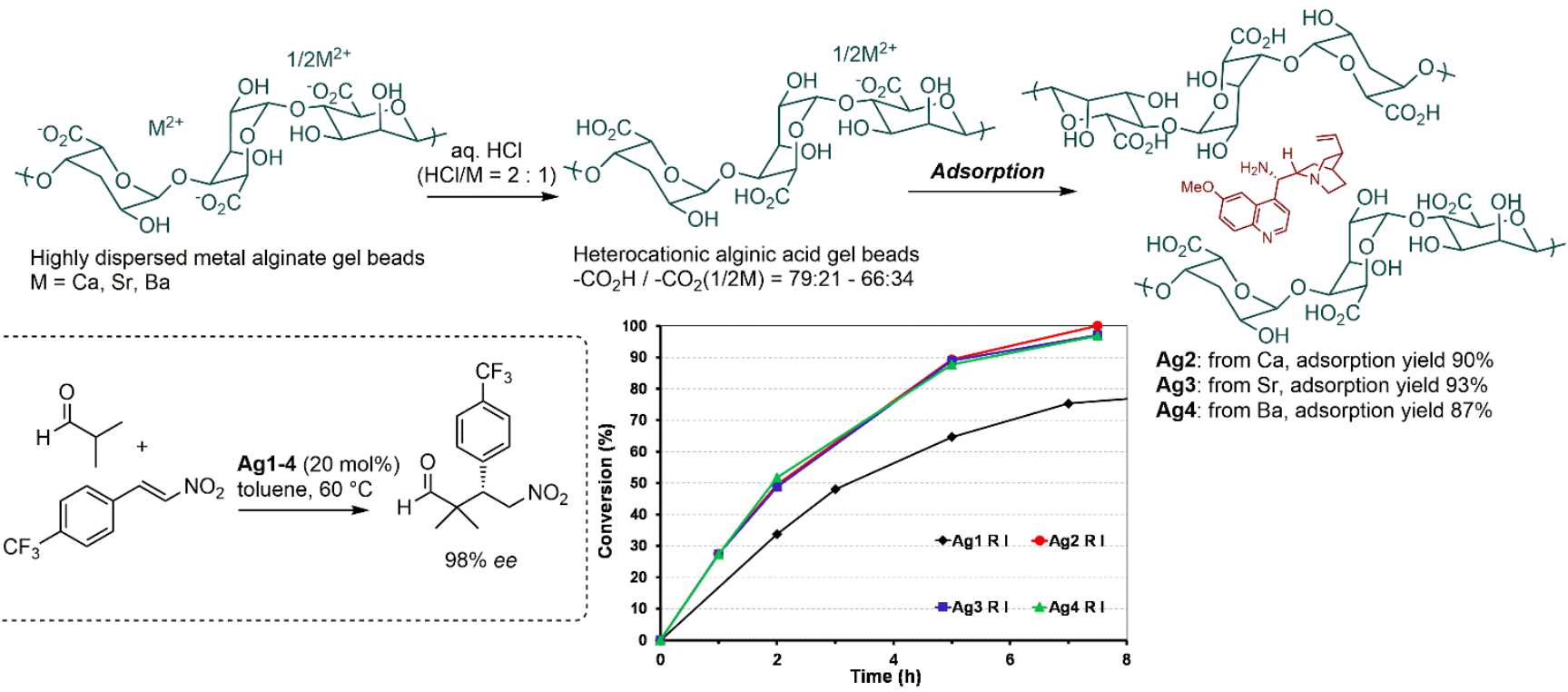

Scheme 11. Preparation of heterocationic alginic acid gels, adsorption of 9-amino-9-deoxy epi-quinine, and kinetics of the catalysis of Ag1-4

Sheldon tests demonstrated again good heterogeneity of the catalysis of Ag2-4, suggesting minimal catalyst leaching during the catalytic process. However, while the beads appeared macroscopically undamaged after the reaction and were easily recovered from the mixture, their reuse provided only disappointing results in terms of activity, even if better than the ones obtained with Ag1. Control experiments suggested that the main reason for deactivation of Ag1-4 was pore occlusion, due to reaction of the biopolymer functionalities with the aldehyde donor, which had to be used in excess (5 equiv.) in the reaction. Conversely, a brief investigation of the reaction scope, with gel catalyst Ag2, showed that several aldehydes and nitroalkene substrates could be engaged in this heterogeneous catalytic transformation with good results, especially in terms of enantioselectivities (Scheme 12). Repeating both adsorption and catalytic protocol with the pseudo-enantiomeric form of the amine catalyst (9-amino-9-deoxy epi-quinidine) gave essentially the same results, in terms of reaction kinetics and enantioselectivity. It was concluded that the homochirality of the biopolymer does not exert any influence on these processes.

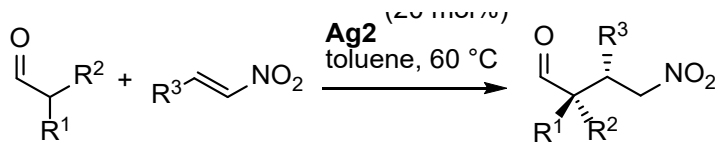<smiles>[X]c1ccc(C(C[N+](=O)[O-])C(C)(C)C=O)cc1</smiles>

$\mathrm{X}=\mathrm{H}, \mathrm{CF}_{3}$

$\mathrm{Cl}, \mathrm{OMe}$ : $65-88 \%$ Yield $95-98 \%$ ee

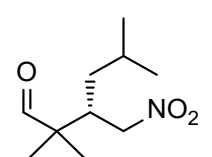

$63 \%$ Yield $97 \%$ ee
$63 \%$ Yield

$20 \cdot 1 \mathrm{~d} r$.

$85 \%$ ee

Scheme 12. Scope of the addition of aldehydes to nitroalkenes catalysed by Ag2: selected results.

\section{Marine polysaccharides as chiral inducing elements in catalytic enantioselective reactions}

Among the common marine polysaccharide families treated in this minireview (chitin/chitosan, alginates, K-carrageenans), only chitosan has received attention as a chiral inducing agent for enantioselective transformations. Amine groups are exceedingly common in enantioinducing elements for organic synthesis (ligands for metals, chiral auxiliaries, resolving agents, organocatalysts, etc.). The presence of an amino function in chitosan has perhaps steered most efforts to use the homochirality of polysaccharides towards this polymer. In fact, the amine functional group can be considered as a possible linchpin for the transfer of the chirality from the polymer to substrates or to anchored, catalytically active, units.

Before considering the use of chitosan in enantioselective catalytic processes, it is worth to highlight its early usage as a chiral reagent. In a series of papers, from mid 1980s' until 2002, Kurita and co-workers have studied the reactivity and the stereoselectivity of chitosan-dihydronicotinamide conjugates in the biomimetic reduction of ethyl benzoyl formate. ${ }^{[29]}$ These studies indicated the importance of a spacer linking the biopolymer to the NADH mimic. Moderate enantioselectivities could be achieved in the reactions performed in acetonitrile and in the presence of the achiral Lewis acid magnesium perchlorate, to activate the $\alpha$-keto ester, using chiral amino acid spacers. The reagents are heterogeneous in nature; they can be recovered from the reaction mixture, and reused upon reduction restoring the dihydronicotinamide function. Most of the enantioinduction offered by these systems was ascribed to the chiral spacer, since amino acid antipodes gave enantiomeric products. However, early attempts using water soluble chitin, that is with a $50 \%$ degree of deacetylation, without spacer (Ct1), indicated a moderate level of enantioinduction, measured by optical rotation, even if accompanied by a low yield (Scheme 13). Lower optical purity was observed by using glycine as achiral spacer, in 
chitosan conjugate Ch12. Thus, even the biopolymer itself was able to induce enantioselectivity in these reactions.
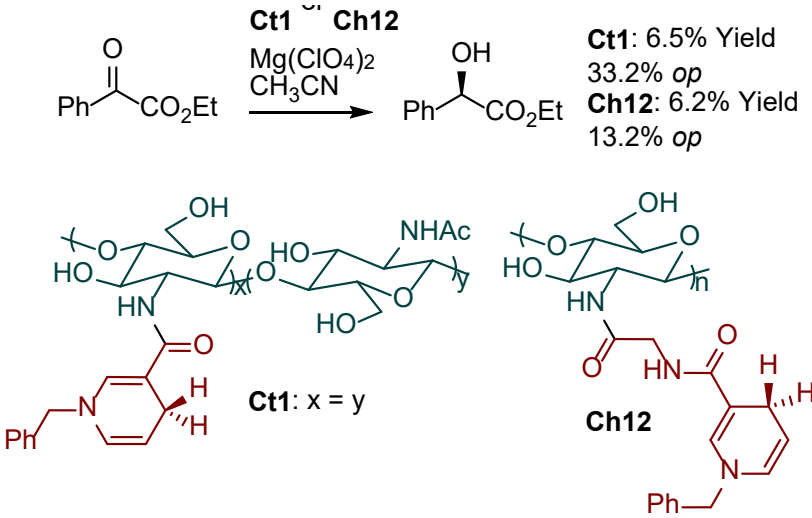

Scheme 13. Dihydronicotinamide-chitin/chitosan conjugates $\mathrm{Ct} 1$ and $\mathrm{Ch12}$ as chiral reagents. $o p=$ optical purity.

The use of chitosan as catalyst to induce enantioselectivity in an asymmetric reaction can be instead traced back to a work by Yuan and co-workers, published in 1999.[30] Several silica supported chitosan-palladium complexes (Ch13) were prepared and evaluated as chiral catalysts in the asymmetric hydrogenation of pro-chiral ketones. The preparation of these catalysts is straightforward (Scheme 14). The first step involves chitosan dissolution in acetic acid/water, followed by addition of silica (surface area $90 \mathrm{~m}^{2} / \mathrm{g}$ ), and base induced deposit of the chitosan on silica. The resulting material, with a $0.79 \mathrm{wt} \%$ nitrogen content, as determined by elemental analysis, is then treated with palladium dichloride under heterogeneous conditions. Considering that all palladium is integrated into the solid, the palladium content in the ultimate material, i.e. the $\mathrm{Pd} / \mathrm{N}$ ratio, could be controlled by the amount of palladium dichloride added in this step. Filtration and drying afford the putative palladium complexes Ch13 as grey solids. Coordination of two nitrogen atoms to the metal was confirmed by X-ray photoelectron spectroscopy analysis.

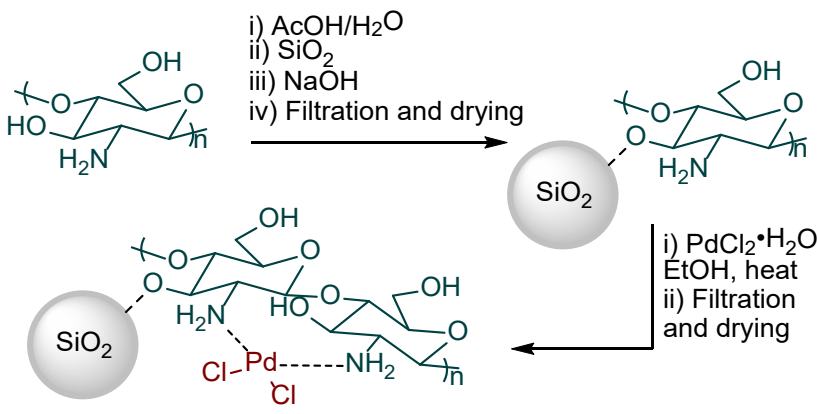

Ch13: N/Pd 1.9-4.7

[Pd content: $0.30-0.12 \mathrm{mmol} / \mathrm{g}$ ]

Scheme 14. Preparation of silica-chitosan-palladium complexes Ch13

Solids Ch13 were then used as catalysts in the hydrogenation of some ketones: acetophenone, propiophenone, 3-methyl-2butanone, 4-methyl-2-pentanone (Scheme 15, top). Even if slightly different results were obtained at different $\mathrm{Pd} / \mathrm{N}$ ratios, the influence of this catalyst parameter could not be rationalized.
Nevertheless, the enantioinduction offered by the system, measured unfortunately by optical rotation, was outstandingly high. Nearly enantiopure alcohols were obtained from three out of the four substrates employed. Preliminary experiments indicated that the selectivity of the heterogeneous catalyst, when recovered and reused, lowered in the case of 4-methyl-2-pentanone. Instead, the catalyst could be used for multiple runs with essentially unchanged results for 3-methyl-2-butanone.

Later, one of these complexes Ch13 was used by Lu and coworkers in the transfer hydrogenation reaction of acetophenone (Scheme 15, bottom). ${ }^{[31]}$ The results obtained, in terms of enantioinduction, are lower than the ones furnished by Ch13 in the hydrogenation with molecular hydrogen. The higher temperature of the transfer hydrogenation, compared to the hydrogenation $\left(>70{ }^{\circ} \mathrm{C}\right.$ vs $\left.30^{\circ} \mathrm{C}\right)$, might be the reason for this difference. Moreover, very low yields $(<2 \%)$ were achieved, indicating an overall poorly efficient process. However, the enantioenrichment of the small amount of alcohol formed was measured by chiral stationary phase gas chromatography, thus reinforcing the reliability of these results.
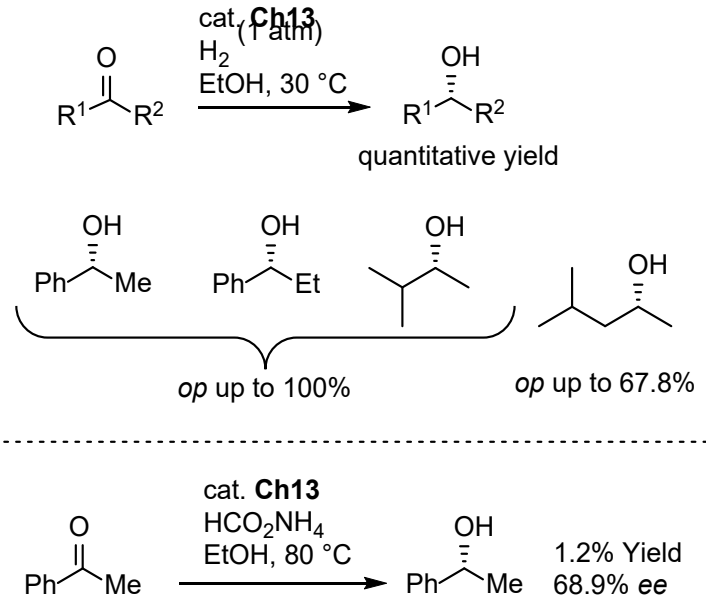

Scheme 15. Hydrogenation of pro-chiral ketones with silica-chitosan-palladium complexes Ch13.

In a similar fashion, other inorganic supported chitosan metal complexes were prepared by the same laboratory that had disclosed Ch13, and used as chiral catalysts for enantioselective hydrogenation reactions (Figure 2). For example, the bimetallic iron-nickel silica supported chitosan derivative Ch14 was prepared and used in the hydrogenation reactions of acetophenone and propiophenone. ${ }^{[32]}$ The reactions, proceeding under forcing conditions $\left(>90^{\circ} \mathrm{C}, 50 \mathrm{~atm}\right)$, gave the corresponding alcohols with op's up to $91.7 \%$. Another silica supported bimetallic system (Ch15) encompassed platinum and iron as the metallic components. ${ }^{[33]}$ This structure, which showed good reusability potential, was found to be active and selective (up to $85.4 \%$ op) in the hydrogenation of 2-hexanone and methyl acetoacetate. In addition, a different inorganic support (MgO) was employed for the preparation of the chitosan-rhodium complex Ch16. ${ }^{[34]}$ This recyclable catalyst was applied to the hydrogenation of 2,3butanedione and 2,4-pentanedione, with op's up to 87.0 and $81.2 \%$, respectively. No information regarding the diastereoselectivities of these latter reactions were reported. 

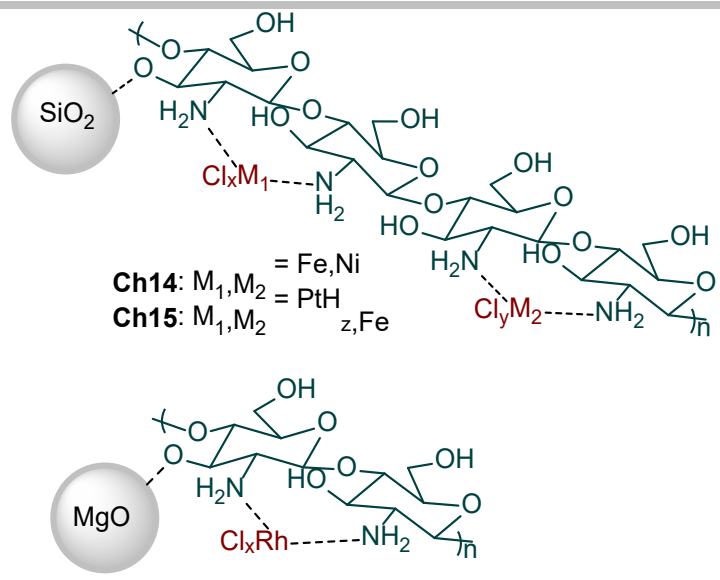

Ch16

Figure 2. Inorganic-chitosan-mono and bimetallic complexes Ch14-16

These works are subjectable to criticism, mainly for the widespread utilization of rotatory power for the determination of enantioinduction. In fact, these results were recently defined as "uncertain, irreproducible". ${ }^{[35]}$ However, they challenge the idea of using chitosan as chiral ligand for transition metals. At any rate, it may be argued that the potential of the homochirality of this biopolymer for enantioselective reductions was unlocked only more recently, when two laboratories described their investigations on the combination of ruthenium and chitosan for the transfer hydrogenation of ketones. These approaches were likely inspired by the very efficient Noyori's ruthenium (II)-1,2diamine system, ${ }^{[36]}$ prompting the authors to test chitosan as an appealing chiral primary amine surrogate.

In 2012, Gagnon, Fontaine and their co-workers described the first example of this approach, using a functionalized chitosan to anchor a ruthenium $p$-cumene complex (Scheme 16). ${ }^{[37]}$ Aiming at obtaining a homogeneous system, facilitating anchoring, characterization and catalysis, chitosan (high molecular weight) was functionalized at its primary alcoholic function. This required protection of the amino function prior to functionalization. Thus, treatment of phthalimido chitosan with pivaloyl chloride, followed by removal of the phthalimido group by hydrazinolysis, gave the polysaccharide esterified at the 6-hydroxy group. This species was treated with $\left[\mathrm{Ru}(p \text {-cymene }) \mathrm{Cl}_{2}\right]_{2}$ in $\mathrm{MeOH}$, resulting, after purification using ultrafiltration and evaporation, in complex Ch17 as an orange solid. The ratio between ruthenium and chitosan monomers - that is, the amine functions - was found to be 0.33 by energy dispersive X-ray spectroscopy. The presence of the pivaloyl ester makes $\mathbf{C h 1 7}$ soluble in $\mathrm{MeOH}$. NMR characterization was performed, confirming coordination of the metal to the amino groups of chitosan. While it was unclear if one or two amines coordinated to the metal in pre-catalyst Ch17, control experiments suggested that the ruthenium should bear two amine ligands during the catalytic process.

Screening of reaction conditions for the transfer hydrogenation reaction with acetophenone indicated the importance of performing the process under inert $\left(\mathrm{N}_{2}\right)$ atmosphere. Variation of other parameters (base, loading, temperature), resulted in the optimized conditions reported in Scheme 16, which, applied to different aryl ketones, furnished the corresponding alcohols in moderate to good yields and enantioselectivities (measured by chiral stationary phase GC). Despite the solubility of Ch17 under the reaction conditions, the anchoring of ruthenium to a polymeric support could nevertheless facilitate its recovery by e.g. a solvent switch - and its reuse. However, it was observed that degradation of the biopolymer under basic conditions occurred, presumably by cleavage of the ester group, preventing the recovery of integral $\mathbf{C h 1 7}$ and its reuse in subsequent reaction cycles.

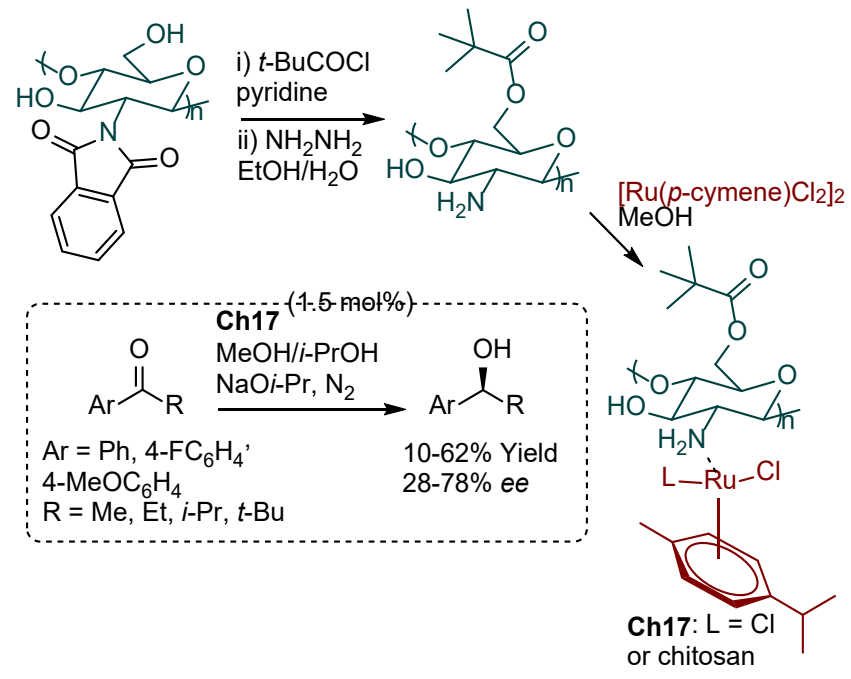

Scheme 16. Ruthenium-chitosan complex Ch17, and its use in the enantioselective transfer hydrogenation of aryl ketones.

More recently, Szöllősi and co-workers reported an interesting and ample study on the combination of ruthenium and chitosan for the transfer hydrogenation of ketones. ${ }^{[35,38]}$ Compared to the approach reported in Scheme 16 with O6-esterified chitosan, these authors simplified the system by complexing the ruthenium salt $\left[\mathrm{Ru}(p \text {-cymene }) \mathrm{Cl}_{2}\right]_{2}$ with unmodified, high molecular weight, chitosan, resulting in Ch18 (Scheme 17). This complex, prepared in situ, was then tested in the transfer hydrogenation of acetophenone. These experiments highlighted the strong influence of the reaction medium on this reaction. A mixture of $i$ $\mathrm{PrOH} / \mathrm{H}_{2} \mathrm{O}$ 1:4 was found to be optimal, and allowed to surpass the results obtained with esterified Ch17. The alcohol derived from simple acetophenone was in fact obtained with a respectable $78 \%$ ee, while substrates bearing substituent(s) at the meta position(s) of the phenyl ring resulted in even higher enantioinductions. Moreover, with catalyst Ch18 inert atmosphere was not required. 


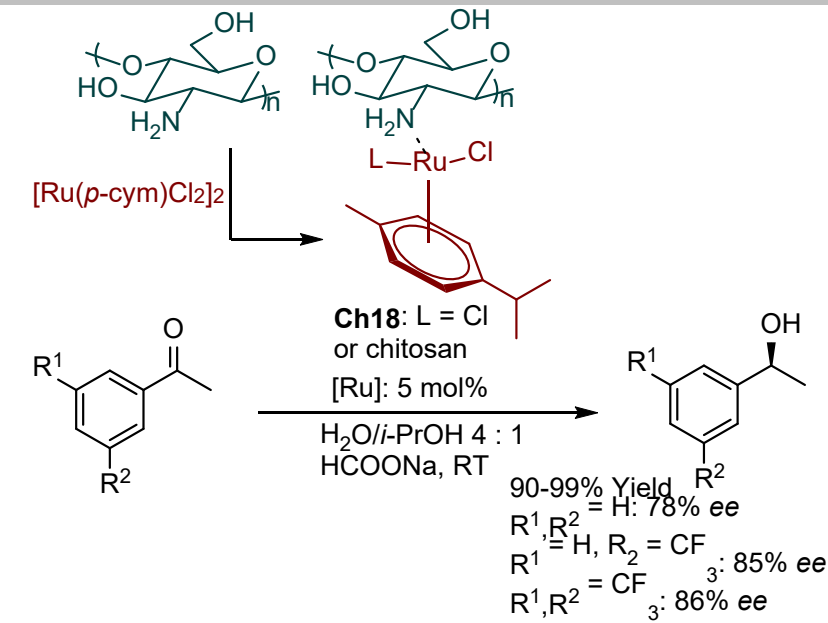

Scheme 17. Enantioselective transfer hydrogenation of acetophenones catalysed by Ch18.

The ratio between the chitosan and metal catalyst precursor did not have a strong influence on the reaction enantioselectivity, with uniformly high enantiomeric excesses observed even by using a molar excess of metal precursor compared to the amine functions. This implies that the active and enantioselective catalyst is already formed even at low chitosan content. However, a $>1$ molar ration between the amino groups and chitosan was required for high conversion. The catalyst could also be prepared ex situ by simply adding the components (ruthenium salt and chitosan) in water, followed by slow evaporation. The resulting orange film could be stored for at least one year. It was characterized by Scanning Electron Microscopy, FT-IR and FTfar-IR spectroscopies, and even, upon dissolution under acidic conditions, by NMR spectroscopy. These techniques indicated a structure for pre-catalyst $\mathrm{Ch} 18$ related to the one proposed for esterified Ch17, which entails coordination of at least one of the amines to the metal. This pre-catalyst $\mathbf{C h 1 8}$ results soluble in the reaction medium, while addition of the base (sodium formate) causes the formation of a yellow precipitate, which further evolves to a pale orange species during the transfer hydrogenation reaction. Nevertheless, catalysis appears far from being heterogeneous. In fact, catalyst recovery and reuse were not investigated. Mechanistically, a ruthenium hydride species forms from pre-catalyst Ch18 upon base assisted hydrogen transfer from the donor $(i-\mathrm{PrOH})$. A possible reaction model for the catalytic reaction was proposed, entailing the involvement of two amines in ruthenium coordination, with an outer sphere metalligand bifunctional mechanism for the hydrogen transfer to the ketone moiety (Scheme 18).

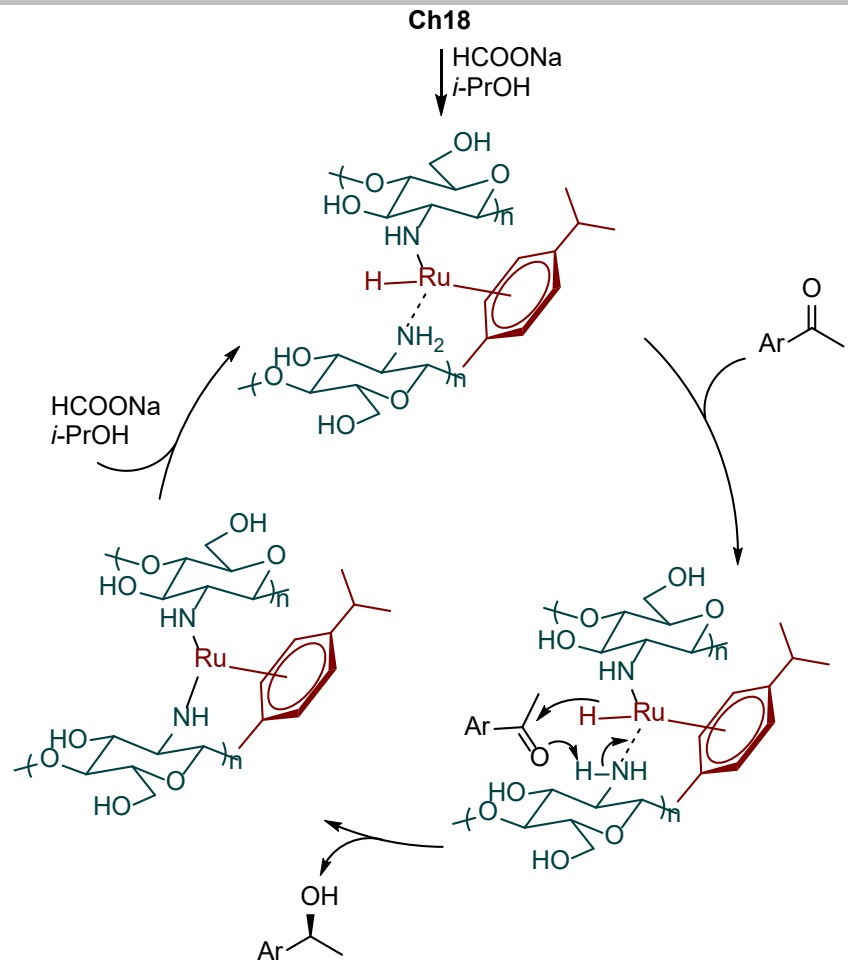

Scheme 18. Proposed catalytic cycle for the transfer hydrogenation reaction.

An exceedingly thorough investigation of the reaction scope was carried out. This study, which included examples on a relatively large scale $(1-8 \mathrm{mmol})$, indicated a variability of the enantioselectivity of the reaction on the structure of the ketone employed. While we refer to the primary literature to get a full picture of the scope of the reaction, ${ }^{[35,38]}$ it is worth to highlight here the remarkable results obtained with benzofused, cyclic ketones, as shown with a selection of examples in Scheme 19. With the exception of the flexible 1-benzosuberone substrate, various cyclic ketone derivatives reacted with outstanding enantioselectivities. Even some heteroatom-containing substrates, despite their propensity to metal coordination, reacted in a highly productive and enantioselective fashion.

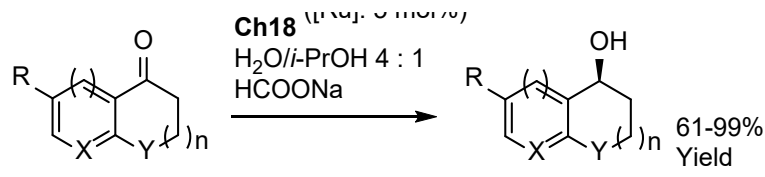

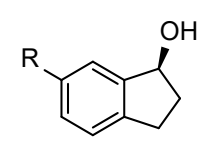

$\mathrm{R}=\mathrm{H}: 88 \%$ $\mathrm{R}=\mathrm{CF}_{3}: 92 \%$<smiles>[R]c1ccc2c(c1)[C@H](O)CCS2</smiles>

$\mathrm{R}=\mathrm{H}: 97 \%$ ee

$\mathrm{R}=\mathrm{Me}: 96 \%$ ee

$\mathrm{R}=\mathrm{Cl}: 97 \%$ ee
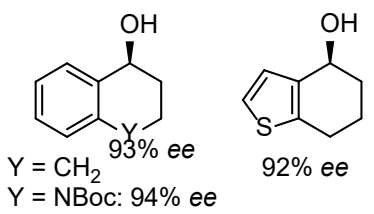

$92 \%$ ee<smiles>O[C@H]1CC[Y]c2ncccc21</smiles>

$\mathrm{Y}=\mathrm{CH}_{2}: 91 \%$ ee

$Y=\mathrm{S}: 93 \%$ ee

$\mathrm{Y}=\mathrm{NMe}: 86 \%$ ee<smiles>O[C@H]1CCCc2ccncc21</smiles>

$79 \%$ ee<smiles>[R]c1ccc2c(c1)[C@H](O)CCO2</smiles>

$\mathrm{R}=\mathrm{H}: 96 \%$ ee $\mathrm{R}=\mathrm{Cl}: 96 \%$ ee<smiles>CCCC[C@H](O)c1ccccc1S(=O)(=O)O</smiles> 
Scheme 19. Selected examples of the transfer hydrogenation of benzo-fused ketones catalysed by Ch18.

Several control experiments were set to gain insights on the structural features of the polymer enabling enantioinduction in these reactions (Scheme 20). While the viscosity of the polymer, which is related to its the molecular weight, did not seem to influence strongly the stereochemical outcome, as verified with a low viscosity chitosan, a complex derived from $\mathrm{N}$-phthalimido protected chitosan was poorly active in the reaction, as expected. The importance of the free primary amine was further demonstrated by a reaction performed using chitin, instead of chitosan. The low conversion and relatively high enantioselectivity of this reaction were ascribed either to partial deacetylation of chitin, or to some weak and un-efficient interaction of ruthenium with its amido or hydroxy groups. In fact, the hydroxy groups of chitosan were not found to be strictly necessary. A catalyst derived from $\left[\mathrm{Ru}(p \text {-cymene }) \mathrm{Cl}_{2}\right]_{2}$ and O-permethylated chitosan, gave the product with results comparable, yet slightly lower, than catalyst Ch18. Use of chitosan monomer glucosamine, or its galactosamine diastereoisomer, gave dramatically worse outcomes, highlighting the importance of polymeric structure in achieving optimal results. Overall, these experiments confirmed the plausibility of the catalytic cycle for the transfer hydrogenation reaction sketched in Scheme 18, wherein the involvement of two amine units is essential for reactivity.

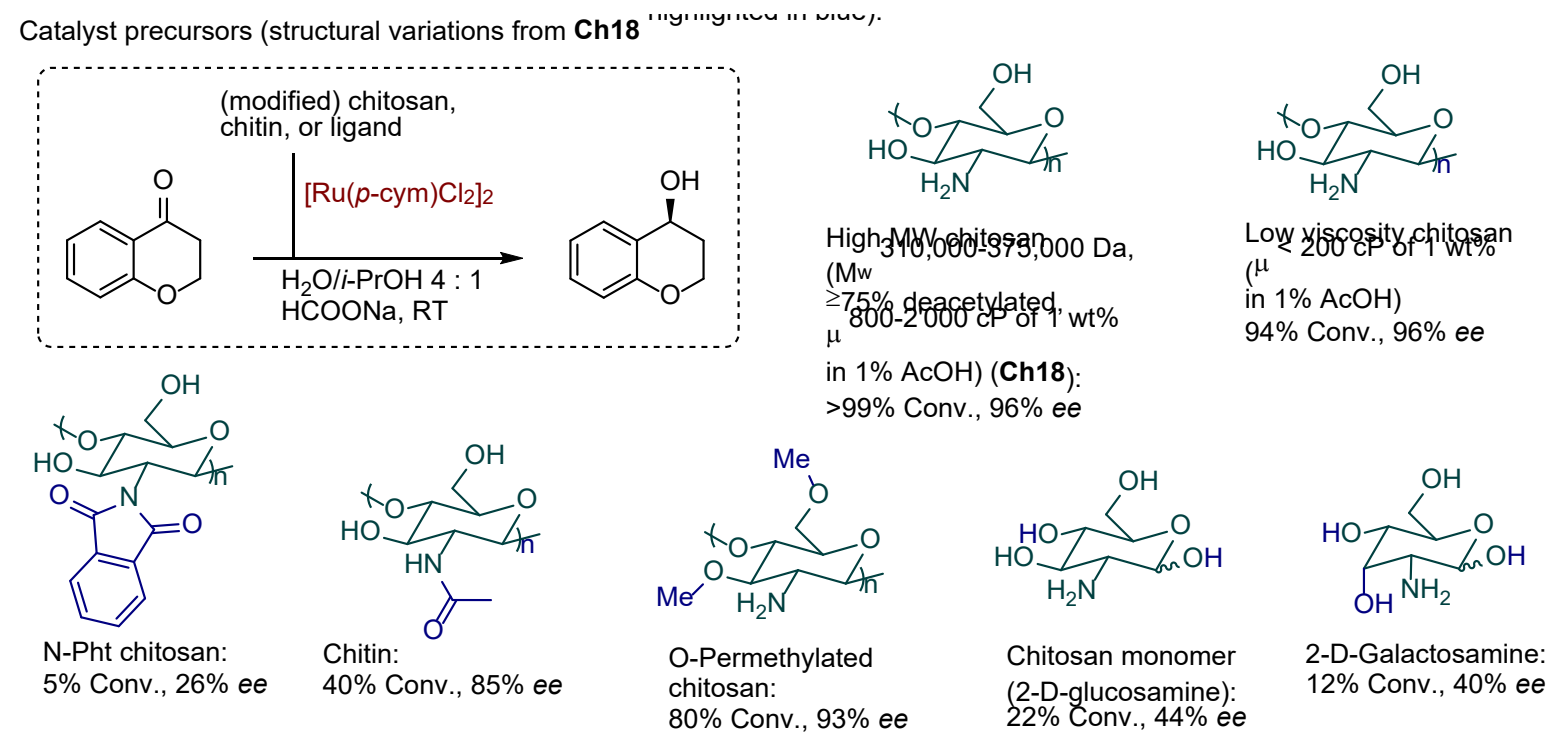

Scheme 20. Control experiments with different catalyst precursors.

Besides these hydrogenation and transfer hydrogenation reactions, other metal-chitosan complexes were prepared and employed in distinct transformations. For example, a silica supported chitosan-cobalt dichloride assembly was prepared along the lines previously reported in Scheme 14 for the palladium complex, and then applied to the enantioselective hydration of 1octene. ${ }^{[39]}$ Albeit undoubtedly a work of great interest, evaluation of the enantioinduction by optical rotation measurements is once again objectionable.

Another approach to the preparation of chitosan-metal conjugates is to manipulate the primary amine of chitosan, to build a ligand able to complex a metallic species. In this context, the formation of Schiff bases has found great utility due to its straightforwardness. ${ }^{[40]}$ This strategy contrasts with previous examples in which the primary amine is directly used to complex the metal. Keeping the focus on enantioselective transformations, Xia and co-workers prepared a series of Schiff bases derived from chitosan and salicylaldehydes, and complexed these ligands with copper acetate. The resulting complexes, of undefined structure, were applied to cyclopropanation reactions of diazoacetates and olefins. ${ }^{[41]}$ Out of the many results reported, the most enantioselective example is highlighted in Scheme 21, wherein the complex Ch20 formed from Schiff base Ch19 and copper acetate promotes the cyclopropanation reaction between tertbutyl diazoacetate and 1-heptene with moderate enantioselectivity. In this case, catalysis is heterogeneous. The catalyst could be recovered by filtration and reused with comparable performances for at least five additional runs.

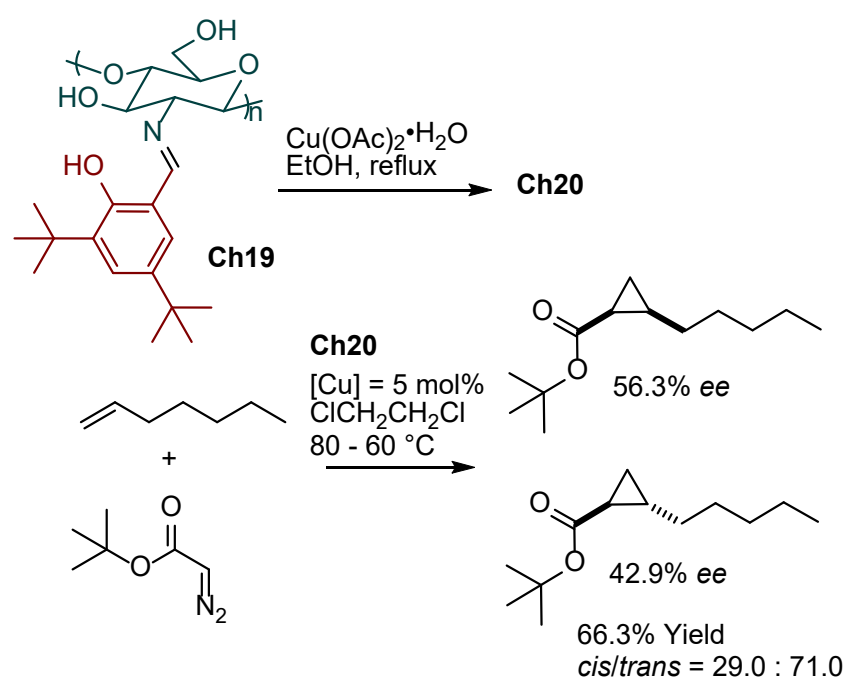

Scheme 21. Enantioselective cyclopropanation reaction catalysed by Ch20. 
A vanadium Schiff base chitosan complex was instead used by Shen and co-workers to catalyse enantioselective sulfoxidations with hydrogen peroxide (Scheme 22). ${ }^{[42]}$ Instead of a simple chitosan ligand, the corresponding silica bound version was employed, to produce the vanadium complex Ch21. Such material proved to a competent and moderately enantioselective catalyst for the sulfoxidation of a range of sulfides, as exemplified in Scheme 22 for the synthesis of the blockbuster antiulcer principle esomeprazole. Furthermore, recovery of the heterogeneous catalyst Ch21 and reuse for at least five cycles was possible.

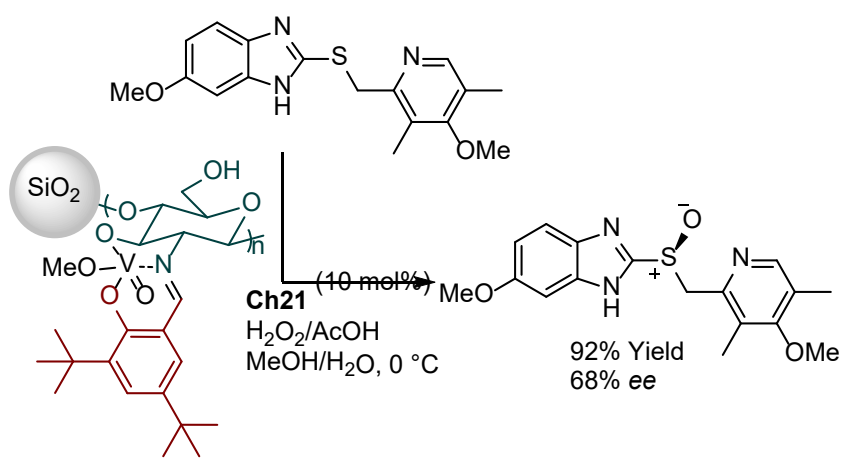

Scheme 22. Enantioselective sulfoxidation to esomeprazole catalysed by silicachitosan-vanadium complex Ch21.

As already mentioned, the studies described so far in this section were likely prompted by the ubiquitous presence of chiral amine ligands for homogeneous metal catalysts. However, the same functional group is also a key player in organocatalysis. Amine containing catalysts, including primary amine ones, are often the catalysts of choice to promote a wide range of organocatalytic asymmetric transformations. In this context, while chitosan has been used as Lewis/Brønsted base catalyst to effect non-asymmetric reactions, ${ }^{[9]}$ its employment in the asymmetric catalysis field seems restricted to the examples reported by our laboratories on the aldol reaction, ${ }^{[43]}$ and to a related study. ${ }^{[44]}$

In more detail, the enantioselective aldol reaction between cyclic ketone donors and electron poor aldehyde acceptors was found to be amenable to chitosan catalysis. The polymer $\mathbf{C h}$, in its aerogel formulation, was used directly in the reaction, without any additional treatment or synthetic manipulation. The addition of cyclohexanone to para-nitrobenzaldehyde was used as the test reaction (Table 2). While the reaction in standard organic solvents, or even under neat conditions, did not proceed (entries 1-3), the use of water as reaction medium resulted in the formation of the aldol adduct in moderate diastereoselectivity but good yield and enantioselectivity (entry 4). Thus, water seems to be essential for the efficacy of this process, which at a closer inspection results biphasic, since the liquid ketone donor is used in large excess (20 equiv.). A remarkable improvement in the enantioselectivity of the process was attained by using acidic additives. Such improvement did not seem to be related to the acidity of these additives, since both 2,4-dinitrophenol (DNP, $\left.\mathrm{p} K_{\mathrm{a}}=4.11\right)$ and stearic acid $\left(\mathrm{p} K_{\mathrm{a}}=10.15\right)$, were found to be effective (entries 5,6). Importantly, using the chitosan monomer (2-D-glucosamine, entry 7 ), the product was obtained with much lower yield and stereoselectivity, highlighting the role of the polymeric structure in this process.

Table 2. Selected results from the screening of reaction conditions in the chitosan aerogel $\mathrm{Ch}$ catalysed aldol reaction between cyclohexanone and paranitrobenzaldehyde.

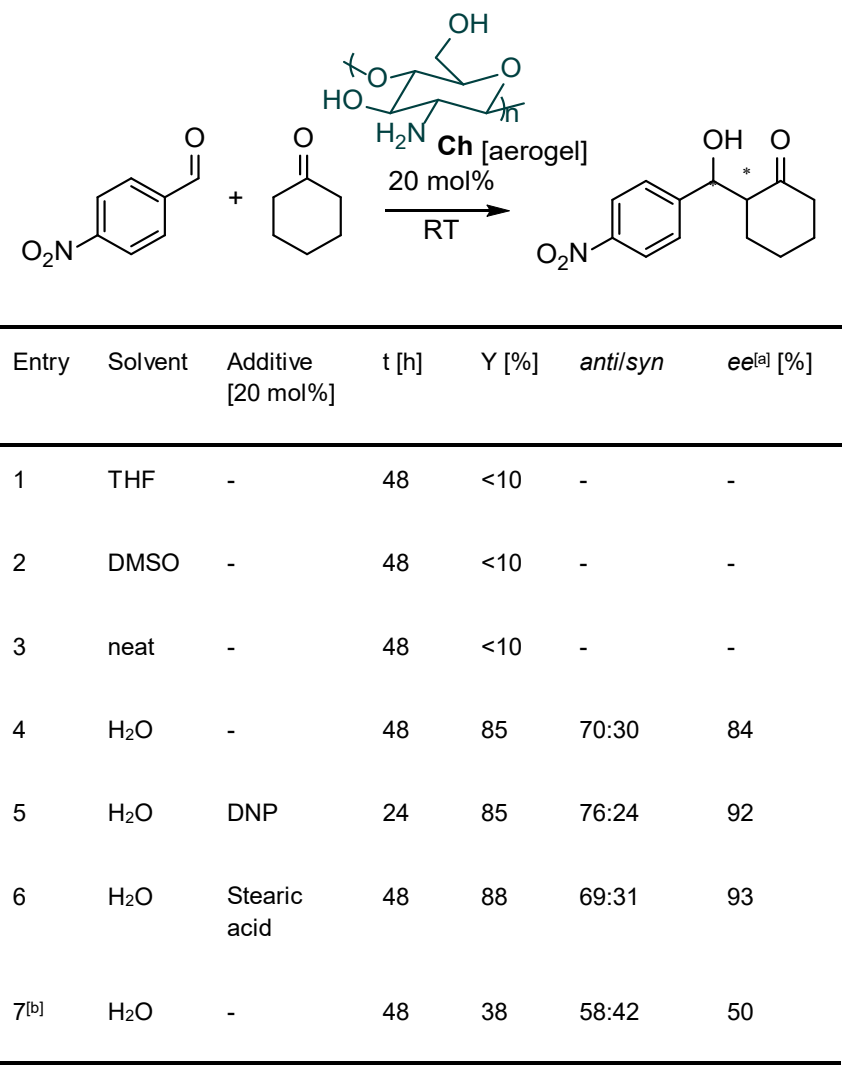

[a] ee of anti diastereoisomer. [b] 2-D-glucosamine (for the structure, see Scheme 18) was used as catalyst.

The scope of the reaction was inspected by using other ketone donors and electron-poor aldehyde acceptors. A selection of examples is reported in Scheme 23. Furthermore, even an activated ketone like isatin was found to participate in the reaction with good results. The possibility to recover and reuse the gel beads for at least three cycles was demonstrated, for the benchmark aldol reaction between cyclohexanone and paranitrobenzaldehyde, performed in the absence of additives. However, while the shape and the aspect of the beads appeared unaffected (thus easily recovered and reused) when cyclohexanone was used as donor, other ketones provoked a considerable macroscopic damage, resulting in disrupture or partial dissolution of the $\mathrm{Ch}$ beads in the aqueous reaction mixtures. 


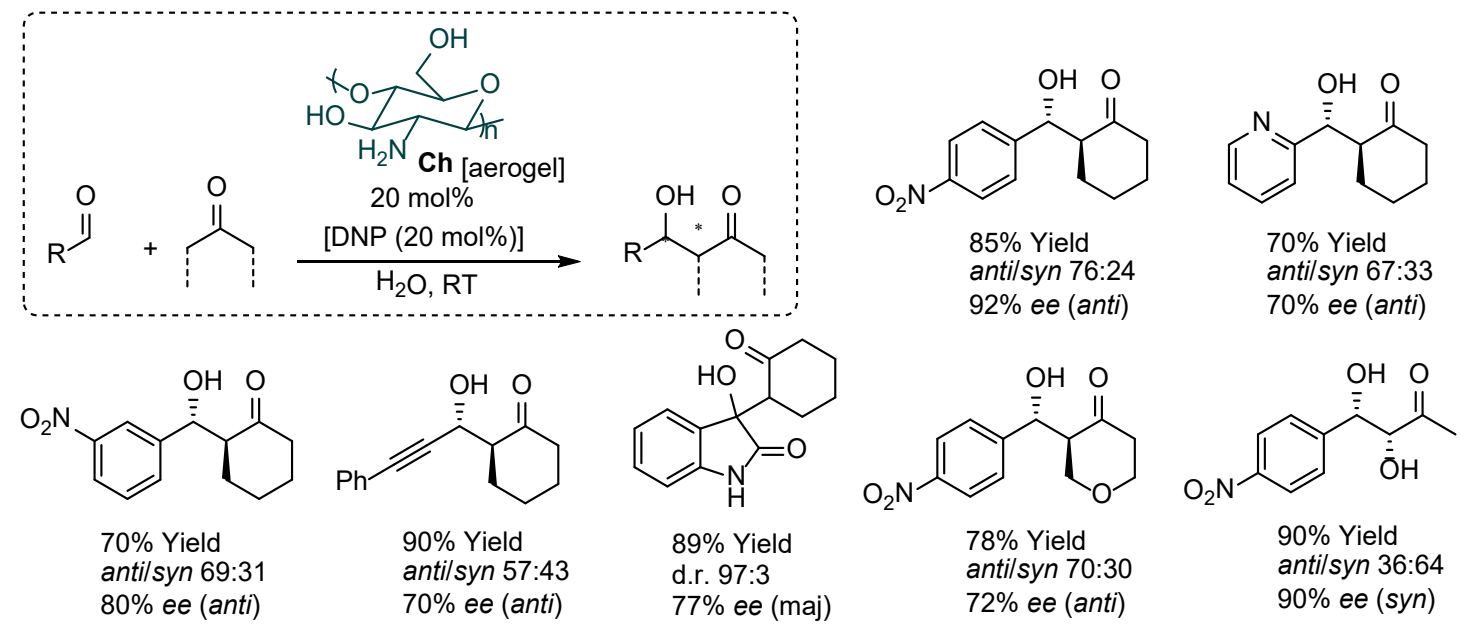

Scheme 23. Scope of the chitosan $\mathrm{Ch}$ aerogel catalysed enantioselective aldol reaction: selected results.

A reaction model accounting for the observed diastereo- and enantioselectivity could be proposed, built on the literature describing other chiral amine catalysed reactions. ${ }^{[45]}$ Such model clarifies also the opposite diastereoselectivities displayed by the reaction with cyclohexanone and tetrahydropyran-1-one donors, compared to the reaction with hydroxyacetone (see Scheme 23). This mechanistic picture (Scheme 24) takes into consideration the intermediacy of an enamine, formed by the condensation of the ketone donor with the primary amino group of the catalyst. It was recognized that acidic additive like DNP can assist this step, while long chain weaker acids like stearic acid might also help the mixing of the substrates with the catalyst, by acting as surfactants, being the reaction biphasic in nature. While cyclohexanone donor results in the formation of an E-enamine, the hydroxyacetone enamine should be mostly present in its Z-form, due to an intramolecular, stabilizing, hydrogen bond interactions. These enamines can react with the aldehyde acceptors, likely activated by a hydrogen bond interaction with the 4-hydroxy group of chitosan. Such arrangements result in the major products observed for the two different donors. However, it could not be excluded that additional hydrogen bond interactions, within the same or with adjacent saccharide units, are taking place. Furthermore, thermodynamic control in these reactions can also have an important role, as already mentioned in the case of proline supported $\mathrm{Ch} 1$ catalysed aldol reaction. ${ }^{[19]}$

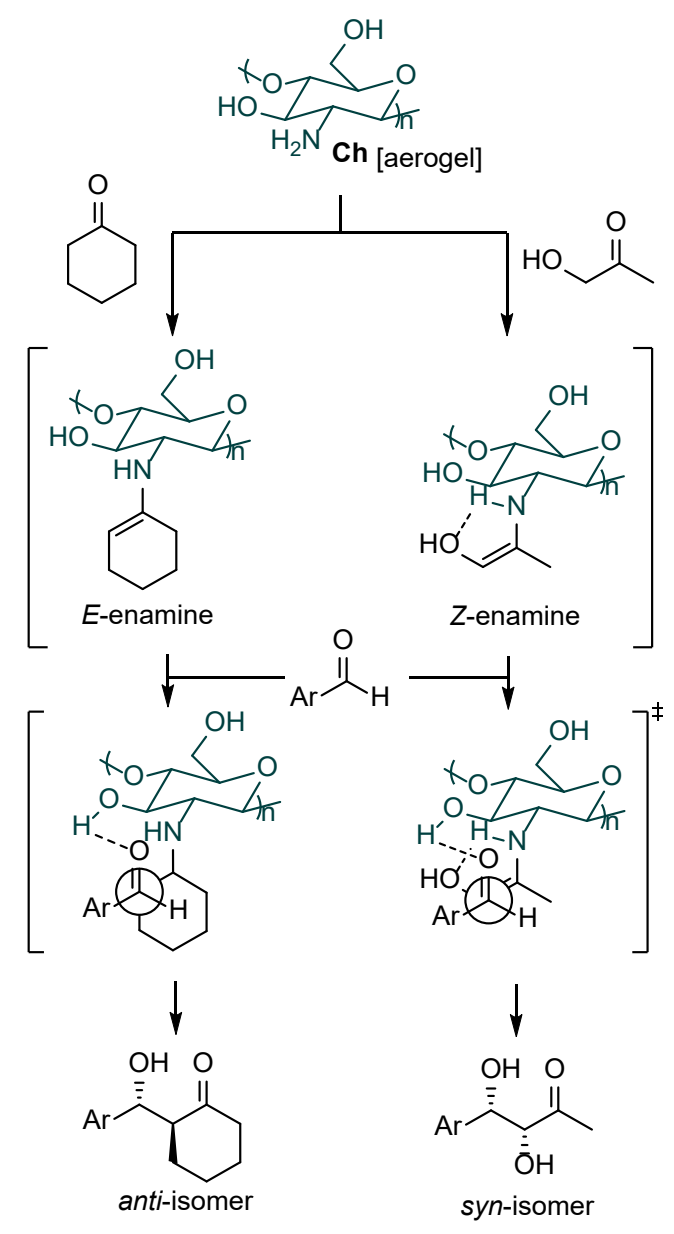

Scheme 24. Mechanistic model accounting for the diastereo- and enantioselectivity of the $\mathrm{Ch}$-catalysed aldol reactions.

The reaction between cyclohexanone and formaldehyde in water without additives did not afford the product (Scheme 25). This lack of reactivity was rationalized considering that, in aqueous medium, this water-soluble acceptor is mostly in its hydrated, non-reactive, form. Taking into consideration the affinity 
of chitosan for fatty acids, ${ }^{[46]}$ as well as the beneficial effect of stearic acid in the test reaction, despite its moderate acidity, it was hypothesized that long aliphatic chain surfactants could assist the reaction by providing a suitable reaction environment. Indeed, by applying anionic (sodium dodecyl sulfate, SDS) or acidic (stearic acid) surfactants to the reaction, it was possible to achieve the formation of the aldol product even with formaldehyde, albeit with only moderate results in terms of both yields and enantioselectivities.

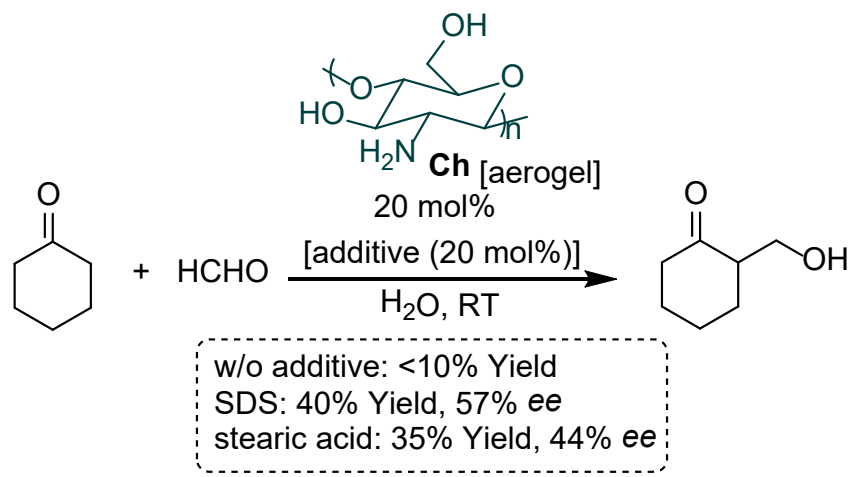

Scheme 25. Chitosan Ch catalysed reaction with formaldehyde acceptor.

An additional important benefit that resulted from the applications of surfactants in these aldol additions was the possibility to reduce the excess of aldol donor required. Using a large excess (20 equiv.) of ketone donor is not an issue for cheap and readily available materials such as cyclohexanone. However, employment of less readily available, yet synthetically attractive, donors - like tetrahydro-4H-thiopyran-4-one or piperidin-4-ones in lower excess would be highly desirable. Indeed, it was found that by using a combination of an acidic additive (DNP) with a surfactant (SDS), the $\mathbf{C h}$ catalysed aldol reactions between these donors and para-nitrobenzaldehyde in water could proceed with moderate efficiency, even by using just two equivalents of these relatively precious substrates (Scheme 26 ).<smiles>O=Cc1ccc([N+](=O)[O-])cc1</smiles>

[2 equiv.]

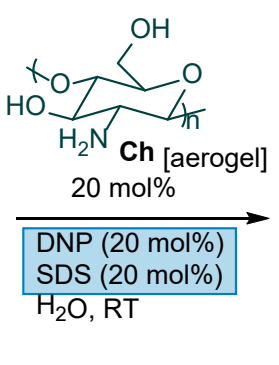

$X=$ NBoc: $83 \%$ Yield anti/syn $75: 25,85 \%$ ee (anti)
Scheme 26. Additive combination to limit the excess of ketone donor in the $\mathbf{C h}$ catalysed aldol reaction.

More recently, the capability of chitosan $\mathbf{C h}$ aerogel in catalyzing aldol reactions in water was applied to the addition of hydroxy and alkoxy acetone to isatins. ${ }^{[44]}$ Also in this case, water proved to be the medium of choice, and a beneficial effect of the utilization of acidic additives was observed. Under the optimized reaction conditions, a range of aldol adducts could be isolated in good yields and variable (from poor to excellent) diastereo- and enantio-selectivities (Scheme 27).

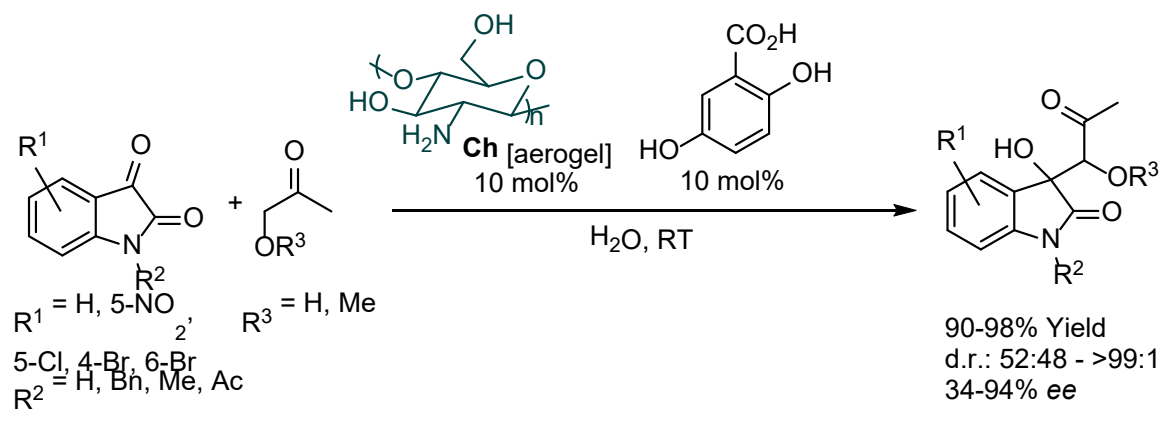

Scheme 27. Enantioselective aldol reaction between isatins and hydroxyl/methoxy acetone catalysed by $\mathrm{Ch}$ aerogel in water.

\section{Conclusions and outlook}

The heterogenization of chiral catalysts through immobilization to insoluble supports has been pursued since the early times of asymmetric catalysis. It has been considered as a linchpin to reduce the cost of a chemical process, by facilitating the recovery and reuse of the precious chiral species. Even if its true utility for the manufacture of fine chemicals, or better the pursuing of this approach instead of searching for more active homogeneous catalysts, has been questioned, ${ }^{[47]}$ examples of the beneficial effect of a support on catalyst performances, in terms of activity and selectivity, are not rare. ${ }^{[48]}$ Furthermore, heterogeneous catalysis opens opportunities in the development of continuous flow catalytic processes, by the use of fixed bed reactors. ${ }^{[49]}$ Last, multistep consecutive reactions involving incompatible catalysts have been made possible through the compartmentalization of the single species in polymer matrixes. ${ }^{[50]}$

In this mini-review, we have shown that these marine polysaccharides can contribute to this field, possibly igniting future applications according to the directions of the above paragraph. To conclude, we add here some deductions which can be drawn from a consideration of the material summarized in the mini-review. 
i) The examples highlighted in section 2 suggest that renewable marine polysaccharides can be used, at least in some cases, as alternatives to depleting oil-based materials to achieve the heterogeneization of organic catalysts. The presence of functional groups in these biopolymers provides unique opportunities for functionalization, compared to other polysaccharides such as cellulose. ${ }^{[51]}$ The most pursued approach has been the covalent derivatisation of chitosan, wherein the amine functionality has been used to anchor the catalytically active species. A non-covalent approach exploiting an acid base interaction between alginic acid and an amine catalyst is also possible. The relatively limited number of examples, however, points to the challenges of this approach: the hydroxyl functions of the polysaccharides might interfere with the catalyst, resulting in catalyst inhibition, and/or with the catalytic process itself, resulting in lower selectivity. Furthermore, modification/degradation of the polymer by reaction with the substrates, can also occur. At the current stage, it is not clear if the reaction environment offered by these gel-like materials can provide a unique and possibly beneficial effect on the catalytic processes, as advanced for other gel systems. ${ }^{[52]}$

ii) The intriguing possibility to use the homochirality of these natural materials as stereoinducing element has been shown with several examples in section 3. The straightforwardness and fascinating nature of this approach to asymmetric catalysis is stunning: a renewable polymeric species can transfer its chirality information, and amplify it through a catalytic process. Recalling the challenges summarized in the introduction, it can be surmised that the main origin of the stereoinduction in these processes is not the tertiary structure of the biopolymer, but rather the local chirality of the single monomeric units. However, the importance of having the monomer embedded in a polymer matrix should not be underestimated. Chitosan is the only marine biopolymer that has been used so far as chirality inducer, with its primary amine acting as a chiral ligand or organocatalyst. The moderate levels of enantioinduction generally observed suggests that chemical modifications might be required, to improve the results and extend the scope and the utility of these reactions. In this context, it is curious to note that many chromatographic enantioseparations are based on modified, silica-bound, polysaccharides (mainly cellulose, amylose, and chitin) as chiral stationary phases. ${ }^{[53]}$ There is a classical parallelism between the chiral recognition phenomena of chromatography and of enantioselective synthesis (three-point interaction model). ${ }^{[54]}$ This suggests that the full potential of the chirality inducing power of these marine species is yet to be unlocked.

iii) Most reports summarized in this mini-review employ the biopolymers in their powder form. We believe instead that the use of their gel counterparts, as shown in the works developed in our laboratories, would bring several distinct advantages. In fact, using aerogels (or hydrogels for reactions in water) guarantees to use dispersed materials of high surface area, without requiring specific reaction media or solvent switches to promote swelling processes in order to expose the functional groups. Furthermore, the gel beads formulation is extremely manageable. Spherical beads of required weight can be easily produced by simple dropwise addition of aqueous solutions of the polymers to baths containing a gelling agent. The characteristics of the single beads, which usually results very similar in terms of shape, size and weight, can be easily controlled by the size of the drop undergoing gelation, that is by the needle used in the dropping process. Last, use of gel beads instead of powders greatly helps the recovery from the reaction mixtures, towards a subsequent reuse. It is exceedingly easier to remove some well-defined spherical beads from a mixture, rather than to filter slurries. It is however true that the beads formulation would not be optimal for flow chemistry. However, it is possible to shape these biopolymers in alternative manners, ${ }^{[55]}$ resulting in films characterized by much better flowability.

\section{Acknowledgements}

We acknowledge co-funding through a SINCHEM Grant. SINCHEM is a Joint Doctorate programme selected under the Erasmus Mundus Action 1 Programme (FPA 2013-17), and the Università Italo-Francese (Galileo program, project number 25966NE, "AEROCAT"). We thank Sara Ramz for the design of the Table of Contents.

Keywords: Alginate $\cdot$ Asymmetric Synthesis • Chitosan • Heterogeneous Catalysis • Renewable Resources

[1] Industrial Biorefineries \& White Biotechnology (Eds.: A. Pandey, R. Höfer M. Taherzadeh, K. M. Napoothiri, C. Larroche), Elsevier, 2015.

[2] a) R. P. Wool, X. S. Sun, Bio-based Polymers and Composites Elsevier Academic Press, 2005; b) F. Quignard, F. Di Renzo, E. Guibal, in Carbohydrates in Sustainable Development I Springer, 2010, pp. 165197; c) Horizons in Sustainable Industrial Chemistry and Catalysis (Eds. S. Albonetti, S. Perathoner, E. A. Quadrelli), Elsevier 2019.

[3] D. J. McHugh, A Guide to the Seaweed Industry, in FAO Fisheries Technical Paper No. 441, FAO, Rome, 2003.

[4] D. Slootmaekers, M. Mandel, H. Reynaers, Int. J. Biol. Macromol. 1990, $13,17-25$.

[5] a) K. I. Draget, O. Smidsrød, G. Skjåk-Bræk, Alginates from Algae in Biopolymers Online (Ed.: A. Steinbüchel), Wiley-VCH, 2005; b) F. Quignard, R. Valentin, F. Di Renzo, New J. Chem. 2008, 32, 1300-1310; c) F. Quignard, F. Di Renzo, E. Guibal, Top. Curr. Chem. 2010, 294, 165-; d) S. Zhao, W. J. Malfait, N. Guerrero-Alburquerque, M. M. Koebel, G. Nyrström, Angew. Chem. Int. Ed. 2018, 57, 7580; Angew. Chem. 2018, 130, 7704.

[6] a) O. Smidrød, Faraday Discuss. Chem. Soc. 1974, 57, 263-; b) K. I. Draget, G. Skjåk-Bræk, O. Smidsrød, Carbohydr. Polym. 1994, 25, 3138.

[7] D. M. Manns, M. M. Nielsen, A. Bruhn, B. Saake, A. S. Meyer, J. Appl. Phycol. 2017, 29, 1493-1506.

[8] A. De Vylder, J. Lauwaert, J. De Clercq, P. Van Der Voort, C. V. Stevens J. W. Thybaut, React. Chem. Eng. 2019, 4, 1948-1956.

[9] Reviews: a) A. Pettignano, D. A. Aguilera, N. Tanchoux, L. Bernardi, F. Quignard, Alginate: a Versatile Biopolymer for Functional Advanced Materials for Catalysis, in Horizons in Sustainable Industrial Chemistry and Catalysis, Ch. 17, (Eds. S. Albonetti, S. Perathoner, A. Quadrelli), Elsevier 2018, 178, 357-376; b) M. Häring, M. Tautz, J. V. AlegreRequena, C. Saldías, D. Díaz Díaz, Tetrahedron Lett. 2018, 59, 32933306; c) E. Guibal, Prog. Polym. Sci. 2005, 30, 71-109; d) D. J. MacQuarrie, J. J. Hardy, Ind. Eng. Chem. Res. 2005, 44, 8499-8520; e) A. El Kadib, ChemSusChem 2015, 8, 217-244; f) O. Mahé, J.-F. Brière I. Dez, Eur. J. Org. Chem. 2015, 2559-2578; g) S. Meninno, ChemSusChem 2019, early view, DOI: 10.1002/cssc.201902500; h) R. S. Varma, ACS Sustainable Chem. Eng. 2019, 7, 6458-6470; i) N. Lucas, A. A. Athawale, C. V. Rode, Chem. Rec. 2019, 19, 1995-2021.

[10] a) F. van de Velde, N. D. Lourenço, H. M. Pinheiro, M. Bakker, Adv. Synth. Catal. 2002, 344, 815-835; b) O. Smidsrød, G. Skjåk-Bræk, Trends in Biotechnol. 1990, 8, 71-78; c) H. J. Kim, J. N. Jin, E. Kan, K. J. Kim, S. H. Lee, Biotechnol. Bioprocess Eng. 2017, 22, 89-94.

[11] a) Recoverable and Recyclable Catalysts (Ed.: M. Benaglia), Wiley, Chichester, 2009; b) A. F. Trindade, P. M. P. Gois, C. A. M. Alfonso, Chem. Rev. 2009, 109, 418-514; c) J. Lu, P. H. Toy, Chem. Rev. 2009, 
109, 815-838; d) S. Itsuno, Md. Mehadi Hassan, RSC Adv. 2014, 4, 52023-52043.

[12] a) M. Benaglia, A. Puglisi, F. Cozzi, Chem. Rev. 2003, 103, 3401-3430; b) T. E. Kristensen, T. Hansen, Eur. J. Org. Chem. 2010, 3179-3204; c) T. Mayer-Gall, J.-W. Lee, K. Opwis, B. List, J. S. Gutmann ChemCatChem 2016, 8, 1428-1436.

[13] R. Valentin, K. Molvinger, C. Viton, A. Domard, F. Quignard, Biomacromolecules 2005, 6, 2785-2792.

[14] R. P. Megens, G. Roelfes, Chem. Eur. J. 2011, 17, 8514-8523.

[15] M. Kaushik, K. Basu, C. Benoit, C. M. Cirtiu, H. Vali, A. Moores, J. Am. Chem. Soc. 2015, 137, 6124-6127.

[16] D. Kühbeck, J. Mayr, M. Häring, M. Hofmann, F. Quignard, D. Díaz Díaz, New J. Chem. 2015, 39, 2306-2315.

[17] H. Zhang, W. Zhao, J. Zou, Y. Liu, R. Li, Y. Cui, Chirality 2009, 21, $492-$ 496.

[18] H. Zhang, L. Zhang, Y. Cui, React. Funct. Polym. 2007, 67, 322-328.

[19] M. Orlandi, M. Ceotto, M. Benaglia, Chem. Sci. 2016, 7, 5421-5427.

[20] Y. Cui, H. Zhang, R. Li, Y. Liu, C. Xu, Chin. J. Org. Chem. 2010, 30, 707712.

[21] Y. Qin, W. Zhao, L. Yang, X. Zhang, Y. Cui, Chirality 2012, 24, 640-645.

[22] W. Zhao, C. Qu, L. Yang, Y. Cui, Chin. J. Catal. 2015, 36, 367-371.

[23] J. M. Andrés, F. González, A. Maestro, R. Pedrosa, M. Valle, Eur. J. Org. Chem. 2017, 3658-3665.

[24] a) R. Pedrosa, J. M. Andrés, A. Gamarra, R. Manzano, C. Pérez-López, Tetrahedron 2013, 69, 10811-10819; b) M. Gruttadauria, F. Giacalone A. Mossuto Marculescu, A. M. P. Salvo, Arkivoc 2009 (viii), 5-15; c) R. Pedrosa, J. M. Andrés, D. P. Ávila, M. Ceballos, R. Pintado, Green Chem 2015, 17, 2217-2225; d) J. M. Andrés, N. de la Cruz, M. Valle, R. Pedrosa, ChemPlusChem 2016, 81, 86-92.

[25] C. A. Mak, S. Ranjbar, P. Riente, C. Rodríguez-Escrich, M. A. Pericàs Tetrahedron 2014, 70, 6169-6173.

[26] P. Riente, C. Mendoza, M. A. Pericàs, J. Mater. Chem. 2011, 21, 7350 7355

[27] D. A. Aguilera, L. Spinozzi Di Sante, A. Pettignano, R. Riccioli, J. Roeske L. Albergati, V. Corti, M. Fochi, L. Bernardi, F. Quignard, N. Tanchoux Eur. J. Org. Chem. 2019, 3842-3849.

[28] L. Zhang, S. Luo, J.-P. Cheng, Catal. Sci. Technol. 2011, 1, 507-516.

[29] a) K. Kurita, Y. Koyama, K. Murakami, S. Yoshida, N. Chau, Polym. J. 1986, 18, 673-679; b) Y. Nishiyama, T. Yoshida, T. Mori, S. Ishii, K. Kurita React. Funct. Polym. 1998, 37, 83-91; c) K. Kurita, M. Hayakawa, Y. Nishiyama, M. Harata, Carbohydr. Polym. 2002, 47, 7-14; d) K. Kurita, T. Nishibori, M. Harata, Biomacromolecules 2002, 3, 705-709.

[30] M.-Y. Yin, G.-L. Yuan, Y.-Q. Wu, M.-Y. Huang, Y.-Y. Jiang, J. Mol. Catal A: Chem. 1999, 147, 93-98.

[31] Y. Sun, Y. Guo, Q. Lu, X. Meng, W. Xiaohua, Y. Guo, Y. Wang, X. Liu, Z. Zhang, Catal. Lett. 2005, 100, 213-217.

[32] D.-Q. Zhou, D.-J. Zhou, X.-H. Cui, F.-M. Wang, M.-Y. Huang, Y.-Y. Jiang, Polym. Adv. Technol. 2004, 15, 350-354.

[33] W.-L. Wei, S.-J. Hao, J. Zhou, M.-Y. Huang, Y.-Y. Jiang, Polym. Adv. Technol. 2004, 15, 287-290.

[34] D.-Q. Zhou, M. He, Y.-H. Zhang, M.-Y. Huang, Y.-Y. Jiang, Polym. Adv. Technol. 2003, 14, 287-291.

[35] G. Szöllösi, V. J. Kolcsár, ChemCatChem 2019, 11, 820-830.

[36] S. Hashiguchi, A. Fujii, J. Takehara, T. Ikariya, R. Noyori, J. Am. Chem. Soc. 1995, 117, 7562-7563.

[37] M. Babin, R. Clément, J. Gagnon, F.-G. Fontaine, New J. Chem. 2012 36, 1548-1551.

[38] V. J. Kolcsár, F. Fülöp, G. Szöllösi, ChemCatChem 2019, 11, 2725-2731

[39] L. Xue, D.-J. Zhou, L. Tang, X.-F. Ji, M.-Y. Huang, Y.-Y. Jiang, React Funct. Polym. 2004, 58, 117-121.

[40] M. Chtchigrovsky, A. Primo, P. Gonzalez, K. Molvinger, M. Robitzer, F. Quignard, F. Taran, Angew. Chem. 2009, 121, 6030-6034; Angew. Chem. Int. Ed. 2009, 48, 5916-5920.

[41] a) W. Sun, C.-G. Xia, H.-W. Wang, New J. Chem. 2002, 26, 775-778; b) H. Wang, W. Sun, C. Xia, J. Mol. Catal. A: Chem. 2003, 206, 199-203.

[42] C. Shen, J. Qiao, L. Zhao, K. Zheng, J. Jin, P. Zhang, Catal. Commun. 2017, 92, 114-118

[43] a) A. Ricci, L. Bernardi, C. Gioia, S. Vierucci, M. Robitzer, F. Quignard, Chem. Commun. 2010, 46, 6288-6290; b) C. Gioia, A. Ricci, L. Bernardi, K. Bourahla, N. Tanchoux, M. Robitzer, F. Quignard, Eur. J. Org. Chem. 2013, 588-594.
[44] H. Dong, J. Liu, L. Ma, L. Ouyang, Catalysts 2016, 6, 186.

[45] S. S. V. Ramasastry, H. Zhang, F. Tanaka, C. F. Barbas, J. Am. Chem. Soc. 2007, 129, 288-289.

[46] P. Wydro, B. Krajewska, K. Hac-Wydro, Biomacromolecules 2007, 8, 2611-2617.

[47] S. Hübner, J. G. de Vries, V. Farina, Adv. Synth. Catal. 2016, 358, 3-25.

[48] B. Altava, M. I. Burguete, E. García-Verdugo, S. V. Luis, Chem. Soc. Rev. 2018, 47, 2722-2771.

[49] a) A. Puglisi, M. Benaglia, V. Chiroli, Green Chem. 2013, 15, 1790-1813 b) C. Rodríguez-Escrich, M. A. Pericàs, Eur. J. Org. Chem. 2015, 11731188; c) I. Atodiresei, C. Vila, M. Rueping, ACS Catal. 2015, 5, 1972 1985

[50] a) X. Fan, C. Rodríguez-Escrich, S. Salayero, M. Pericàs, Chem. Eur. J. 2013, 19, 10814-10817; b) J. Pauly, H. Gröger, A. V. Patel ChemCatChem 2019, 11, 1504-1510; c) J. Pauly, H. Gröger, A. V. Patel, Catalysts 2019, 9, 547 .

[51] T. Yasukawa, H. Miyamura, S. Kobayashi, Chem. Sci. 2015, 6, 6224 6229

[52] a) D. Díaz Díaz, D. Kühbeck, R J. Koopmans, Chem. Soc. Rev. 2011, 40, 427-448; b) E.-M. Schön, E. Marquéz-López, R. P. Herrera, C. Alemán, D. Díaz Díaz, Chem. Eur. J. 2014, 20, 10720-10731; c) W. Fang, Y. Zhang, J. Wu, C. Liu, H. Zhu, T. Tu, Chem. Asian J. 2018, 13, 712 729.

[53] J. Teixeira, M. E. Tiritan, M. M. M. Pinto, C. Fernandes, Molecules 2019 24, 865 .

[54] V. A. Davankov, Chirality 1997, 9, 99-102.

[55] A. Pettignano, N. Tanchoux, T. Cacciaguerra, T. Vincent, L. Bernardi, E. Guibal, F. Quignard, Carbohydr. Polym. 2017, 178, 78-85. 


\section{Entry for the Table of Contents}

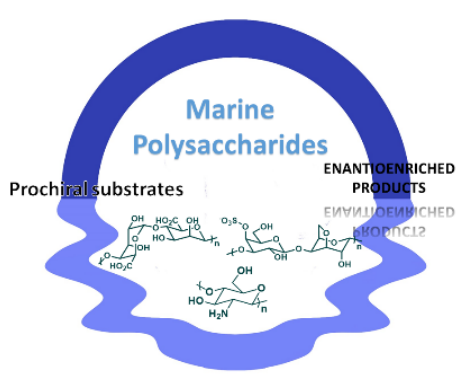

From sea to flask. This mini-review highlights the emerging use in asymmetric catalysis of some polysaccharides (alginate, chitin/chitosan, carrageenan) extracted from marine sources. These versatile renewable materials have been used to support chiral catalysts, and even as chiral inducing elements, to effect a variety of catalytic enantioselective transformations. 